\title{
Excavaciones en Guadalajara: secuencia andalusí desde época Emiral a Taifa y presentación de un singular conjunto numismático
}

\author{
Elena Serrano, Mar Torra, Manuel Castro y Aurelia Sánchez**
}

\begin{abstract}
RESUMEN
A partir de la documentación de una secuencia estratigráfica en la ciudad de Guadalajara se han podido identificar unos materiales andalusíes con dataciones relativas. Se han identificado hasta 4 fases de actividad para el período islámico, con silos, pozos e instalaciones de tipo industrial así como importantes lotes de materiales. Entre ellos, se ha localizado un conjunto de 37 piezas de cobre (monedas o ponderales) de reducidas dimensiones, de forma irregular y un peso no superior a 1,2 grs., con leyendas en epigrafía árabe tales como "La justicia es de Dios" y "Abdallah ibn Muhammad". Esta secuencia es el punto de partida para el reconocimiento de las características que definen las diferentes fases y puede permitir precisar las cronologías de otros yacimientos coetáneos, en general no estratificados, de la Frontera Media. Por otro lado, los conocimientos que se tienen sobre la Guadalajara islámica se han visto incrementados al poder registrar una ocupación continuada desde época emiral en una ciudad de la que apenas se conocían restos de su cultura material.
\end{abstract}

PALABRAS CLAVE: Frontera Media. Secuencia estratigráfica. Cerámicas andalusíes. Cobres islámicos. Cronología.

\section{INTRODUCCIÓN}

El conocimiento arqueológico del sector fronterizo conocido como Marca o Frontera Media durante el periodo islámico resulta limitado si lo comparamos con otros ámbitos peninsulares. Las investigaciones se han centrado, fundamentalmente, en estudios sobre

\begin{abstract}
Starting from the documentation of a stratigraphic sequence in the town of Guadalajara, a number of dates corresponding to materials from the different excavated contexts have been established. There have been identified even four activity phases for the Islamic period including silos, wells or industrial installations as well as significant lots of materials. Among them, there are a group of 37 pieces (coins or weights), small in there size, whith irregular shapes and weighing no more than 1,2 grm. These pieces contain legends in Arabic epigraphy such as "Justice comes from God" and "Abdallah ibn Muhammad". This sequence is the starting point to recognize the defining characteristics of the different phases which enable us to determine chronologies from some sites belonging to the "Frontera Media" (Middle Border) and which in general are not stratified. Furthermore, the knowledge of the Islamic Guadalajara has been increased thanks to the documentation of a continued occupation which begins in the Emiral time in a town whose material culture was hardly known.
\end{abstract}

KEY WORDS: "Frontera Media". Stratigraphic sequence. Islamic pottery. Islamic coppers. Chronologie.

la red viaria, las fortificaciones y la política urbanizadora de los Omeyas, vinculada habitualmente a la posición fronteriza de esta región. Trabajos más recientes han pretendido profundizar en las características del poblamiento en este sector del territorio andalusí a través del estudio de la documentación escrita, la prospección sistemática de asentamien-

* Arqueólogos de Trabajos de Arqueología y Restauración, Soc. Coop. Mad. (info@tar-arqueologia.com). 
tos y la descripción y análisis de los esquemas constructivos de las estructuras localizadas !. Diversos trabajos de prospección han permitido identificar, a partir de la recuperación de cerámicas, una serie de asentamientos, la mayoría de los cuales carecen de referencias textuales a excepción de Alija y quizás Vascos. Sin embargo, una de las conclusiones más generalizadas se refiere a la dificultad de datar los sitios identificados a partir del registro cerámico, dada la práctica inexistencia de yacimientos estratificados.

Por otro lado, y a pesar del gran número de intervenciones arqueológicas realizadas en ámbitos urbanos, todavía carecemos de secuencias fiables para el periodo pre-taifa en ciudades como Madrid, Toledo, Talavera, Talamanca - Guadalajara ${ }^{2}$. Salvo contadas excepciones, por ejemplo Vascos, no se han excavado viviendas o restos del primitivo parcelario, por lo que el desconocimiento sobre la morfología o fases de crecimiento de las ciudades es prácticamente absoluto. Por otro lado, la ausencia de secuencias impide contar con elementos que permitan datar las escasas evidencias que proporciona este registro arqueológico. Un reciente trabajo muestra cómo el desconocimiento de las tipologías cerámicas de los siglos IX d.C. y $X$ d.C. en el interior de al-Andalus es producto de esta general ausencia de estratigrafías (FERNÁNDEZ UGALDE, 200 I).

Una excavación arqueológica realizada en la ciudad de Guadalajara, ha permitido docu- mentar una secuencia estratigráfica poco habitual en el registro arqueológico de la región central de al-Andalus ${ }^{3}$. El análisis de esta secuencia nos permite plantear que los conjuntos cerámicos de época califal, y en general pre-taifa, de la Frontera Media habían resultado hasta la fecha irreconocibles, ya que las variables empleadas para datar determinados contextos o asentamientos, deben ser revisadas a partir de los resultados de yacimientos estratificados. En este sentido, el estudio que presentamos sobre un conjunto numismático procedente de uno de los estratos de amortización de un silo subterráneo, viene a confirmar cómo sólo el estudio de secuencias puede permitir plantear cronologías incluso para este tipo de objetos (CASTRO y SÁNCHEZ, en prensa).

En una primera aproximación al área de estudio se observa que la mayoría de los sitios identificados como islámicos, a partir fundamentalmente de materiales recuperados en trabajos de prospección, son con toda probabilidad de época de Taifas. Falta reconocer, a partir de los ajuares cerámicos, las fases anteriores. Hoy por hoy no existen ni argumentos cronológicos rotundos ni secuencias estratigráficas que permitan asegurar que en el mundo de la Frontera Media lo Califal pasa, entre otras cosas, por la generalización del vidriado y la difusión de técnicas como el verde y manganeso. Se necesitan más registros de sitios estratificados para confirmar, rebatir y completar esta primera presentación ${ }^{4}$.

\footnotetext{
I Por ejemplo, el trabajo de investigación dirigido por S. Martínez Lillo y L. Serrano-Piedecasas (MARTíNEZ y SERRANO-PIEDECASAS, 1998).

2 Por el contrario, para el periodo taifa se han reconocido numerosos contextos que han sido datados en esta época a partir de la documentación de las técnicas de verde y manganeso y cuerda seca, generalmente asociadas. Por ejemplo, en la ciudad de Madrid apenas se conocen —o permanecen inéditos - conjuntos que difieran de las características generalmente admitidas para los ajuares del siglo Xl; en la ciudad de Guadalajara se han publicado materiales catalogados como califales a partir de la presencia de verde y manganeso. En definitiva, salvo contadas excepciones, el siglo XI es reconocido fácilmente a partir de la presencia de las series vidriadas bícromas y polícromas, cerámicas pintadas y repertorios tipológicos con las series clásicas y la fase califal es identificada a partir del verde y manganeso aunque en general se admita que son materiales descontextualizados o procedentes de excavaciones no estratificadas.

3 Los primeros resultados de los trabajos arqueológicos fueron presentados y publicados en Actas del Primer Simposio de Arqueología de Guadalajara, celebrado en Sigüenza entre el 4-7 de octubre de 2000 y en Congreso Internacional Almanzor y su época, celebrado en Córdoba entre el 14-18 de Octubre de 2002, donde presentamos la comunicación "Vivir en la frontera: aportaciones de la arqueología en Guadalajara (siglos X y XI)" (en prensa).

4 Agradecemos a Lucía Román, Esther Corregidor y María Torra su colaboración en el estudio de la documentación generada por la excavación, y a Antonio Fernández Ugalde y Manuel Presas Vías las sugerencias y lectura crítica del documento.
} 


\section{GUADALAJARA ISLÁMICA}

La región central de al-Andalus, y más concretamente la zona fronteriza próxima al Sistema Central, comprende las comarcas atravesadas por la principal vía de comunicación del Estado Omeya: los valles del Guadiana y Tajo (Figural). Según informan las fuentes escritas como Muqtabis V o al-Udri (MANZANO, 1991), este sector fue poblado ya desde fechas muy tempranas por grupos beréberes, en general muy vinculados a zonas de frontera. Aunque la investigación arqueológica en este sentido resulta todavía incipiente, el análisis de la toponimia arroja interesantes datos sobre los asentamientos, y se empieza a contar con análisis de macrotopónimos que parecen indicar un origen beréber tribal, por ejemplo, en la zona comprendida entre Sigüenza y Guadalajara, donde parece haberse preservado un gran número de topónimos arabo-beréberes (FERNÁNDEZ UGALDE, 200 I). Podemos destacar los que mencionan a algún individuo o familia de origen beréber, como Madinat al-Faray de los Banu I-Faray. Recientes estudios realizados a partir del análisis constructivo de fortificaciones (MARTÍNEZ LILLO y SERRANO PIEDECASAS, 1998) han permitido delimitar determinadas zonas de la Marca Media -ribera meridional del Tajo- como territorios dominados por tribus beréberes aliadas con el poder Omeya. Sin embargo aún no nos es posible reconocer la presencia de población beréber a partir del análisis de aparejos, técnicas constructivas o ajuares cerámicos y siguen resultando problemáticas las atribuciones beréberes de algunas formas o tipos cerámicos asignadas en determinados asentamientos, por ejemplo en "Las Fuentecillas" (Madrid) donde los tipos así clasificados son las conocidas "ollas con escota- dura en hombro" o las jarritas de cuello cilíndrico y cuerpo globular (BERMEJO y LÓPEZ, 1996) ${ }^{5}$.

Por otro lado, sólo en fechas recientes se están empezando a reconocer contextos que pueden datarse provisionalmente en las primeras fases del periodo andalusí. Un reciente trabajo de síntesis (OLMO, 2002) plantea, a partir de los resultados obtenidos fundamentalmente en el yacimiento de Recópolis, en asentamientos como El Turmielo, o la reinterpretación de otros como El Castro de la Coronilla, la existencia de claras evidencias arqueológicas que son interpretadas como el reflejo de una ruptura con la fase anterior, de época visigoda, datada en el siglo VIII d. C. Esta fase se caracteriza por una aparente continuidad en los aspectos tipológicos del registro arqueológico ${ }^{6}$ constatada en yacimientos como el propio Recópolis, Segóbriga o Ercávica, e interpretada como indicadora de la debilidad de una estructura social y la implantación de una nueva. A lo largo de este siglo, y siempre a partir del referente cerámico, se plantea la creación de nuevos asentamientos a menudo en antiguos castros de la Edad del Hierro, o en lugares no habitados hasta ese momento. Entre los yacimientos de este tipo se encuentran El Turmielo (Aragoncillo, Guadalajara) y el Castro de la Coronilla (Chera, Guadalajara).

Sin embargo, Olmo insiste en que la ausencia de secuencias estratigráficas obliga a ser cautos, ya que yacimientos datados a finales del VIII d. C., a partir del material cerámico, pueden ser del siglo IX d. C. En general, se asume que las dataciones nunca deberán llevarse al siglo $X$ d. C. por la ausencia de materiales de esa cronología. Durante la primera mitad del siglo IX d. C. se fundaron nuevos centros como

\footnotetext{
5 En este sentido resulta muy interesante la sugerencia planteada por BOONE Y BENCO (1999) sobre la tradición cerámica beréber: si los beréberes norteafricanos fueron los responsables de muchos asentamientos rurales peninsulares, se debería esperar que su tradición cerámica, lo mismo que otros aspectos de su bagaje cultural, fuera la misma que la que se documenta en el Norte de África, donde se observa que la pervivencia de la cerámica a mano, es una de las características de estos asentamientos. Ya G. Rosselló se preguntaba sobre las cerámicas modeladas bereberes y su pervivencia, y argumentaba sobre la dificultad de extrapolación. Ver "Coloquio" en MALPICA, A. Ed. (1993): Primer Encuentro de Arqueología y Patrimonio: La cerámica altomedieval en el sur de alAndalus, Granada, pp. 139-152.

6 Esa continuidad en los aspectos tipológicos se refiere a la pervivencia de ajuares visigodos (aunque con introducción de tipos nuevos como cántaros o candiles y distintas formas de ollas), desaparición paulatina de la mano/torneta, o la continuidad en el paisaje urbano.
} 
Guadalajara, Zorita o Peñafora y se abandonarían los anteriores (por ejemplo, El Turmielo, La Coronilla o el mismo Recópolis). Así, en época califal se produciría "...la consolidación de la hegemonía de la sociedad islámica y del Estado Califal Omeya [...]".

Las excavaciones del área urbana de Guadalajara parecen señalar que fue un centro importante de producción cerámica de esta época, a juzgar por los hallazgos localizados en La Plaza de la Antigua de un alfar, fechado por sus excavadores en el siglo $X$ d.C. por la presencia de cerámica vidriada (CRESPO y CUADRADO, 1992). Otro asentamiento datado en esta fase a partir de los materiales de prospección es Cueva Harzal (Olmedillas, Guadalajara), donde se recuperaron II fragmentos de cerámica islámica, entre los que destacan una "olla con escotadura", un fragmento vidriado interior y exterior en verde, $y$ varios con pintura exterior a trazos. La datación en época califal que proponen los arqueólogos se basa en la presencia de cerámica pintada (VALIENTE y GARCÍA-GELABERT, 1983). Por último, un yacimiento que puede llegar a aportar información sobre el registro cerámico en asentamientos rurales es el de Los Casares (Riba de Saelices, Guadalajara), actualmente en curso de excavación (GARCÍA y FERRERO, 2002).

\section{A. La ciudad de Guadalajara}

Guadalajara, la Madinat al-Faray islámica, ciudad de la Frontera Media, aparece mencionada en las fuentes escritas árabes como centro secundario en relación con Toledo. Estuvo bajo el gobierno de los Banu Salim, linaje beréber de la tribu de los Masmuda que controlaba el territorio comprendido entre Guadalajara y Medinaceli (Soria). Esta zona constituyó a menudo un núcleo de resistencia de grupos de componente beréber contra el poder estatal Omeya. Así, a finales del siglo $X$ d.C., los gobernadores pasaron a ser directamente designados por el poder central. Uno de los más famosos fue Galib, que se hizo fuerte en este sector fronterizo (MANZANO, 1991). Las escasas referencias escritas informan de que Guadalajara era una ciudad fuertemente amurallada, con abundante agua, mercados, posadas y baños. Es en el siglo X d.C. cuando alcanza su máximo esplendor, llegando a ser capital de kûra. Al igual que otras ciudades de este sector fronterizo fue conquistada a finales del siglo XI d.C. En cualquier caso, las informaciones extraídas de las fuentes escritas son poco concluyentes.

En la Guadalajara islámica, situada en la orilla izquierda del río Henares, sobre la vertiente inferior de una ladera perfectamente delimitada por los barrancos del Alamín al Este y de San Antonio al Oeste, los primeros estudios arqueológicos centraron su interés en la morfología urbana. Torres Balbás (TORRES BALBÁS, 1940) y posteriormente B. Pavón (PAVÓN, 1984) informan sobre el primer puesto militar y posterior alcazaba, que se localizaría en el sector central de este promontorio. La primitiva medina se extendería en dirección al Henares hasta enlazar con el puente sobre este río, cuya construcción se data en el s. X d. C. Estudios posteriores, como los de Pradillo y Esteban (PRADILLO y ESTEBAN, 1991) o C. Mazzoli (MAZZOLI, 2000), nos muestran una ciudad con su alcazaba en el centro, que ya en el siglo XI d.C. abarcaba una superficie intramuros de 47,05 ha.

\section{B. Arqueología de la Guadalajara andalusí}

Las intervenciones arqueológicas en Guadalajara (Figura 2), aunque escasas, han revelado indicios de este poblamiento islámico a partir de la recuperación de materiales cerámicos, en general descontextualizados (CRESPO y CUADRADO, 1992). Las principales excavaciones realizadas en la ciudad se concretan en:

- Diversas campañas llevadas a cabo en el interior del Alcázar, cuyos resultados permanecen prácticamente inéditos (CUADRADO, CRESPO y ARENAS, 1998).

- Iglesia de los Remedios, donde se documentaron varios contextos ("bolsadas") fechados en época islámica por los materiales: candiles de piquera, jarritas con decoración pintada, tapaderas, un ataifor vidriado melado con trazos de manganeso y 3 fragmentos decorados con cuerda seca parcial (BARROSO y JIMÉNEZ, 1992). 
- Plaza de la Antigua. Se localizaron vestigios interpretados como pertenecientes a un alfar hispanomusulmán. El repertorio cerámico se refiere a fragmentos bizcochados con decoración de trazos de pintura, vidriadas meladas o verdes, ausencia de verde y manganeso y de cuerda seca, así como al hallazgo de varios atifles y rollos (CRESPO y CUADRADO, 1992).

- Plaza de Moreno, con cerámicas de tipología islámica descontextualizadas (CRESPO y CUADRADO, 1992).

- Palacio de los Guzmán. Se excavaron los restos de la cocina de una casa islámica y se recuperaron conjuntos cerámicos entre los que se encuentran ollas con escotadura en hombro, jarritas y cántaros, destacando la ausencia de cuerda seca y la escasez de cerámica vidriada monocroma. Este conjunto ha sido datado a mediados del siglo X d.C. (CRESPO y CUADRADO, 1992).

- Iglesia de Santa María de la Fuente, Concatedral de Guadalajara, donde sobre una tumba en fosa, datada en época visigoda o postvisigoda, se documentaron restos de un muro con zócalo de piedra y alzado de tapial o adobe que parece corresponderse con el final de la época islámica, ya que se le apoyaba un estrato con materiales cerámicos entre los que cabe destacar: verde y manganeso y pintadas (PRESAS, 2002).

Debemos señalar que ninguna de estas intervenciones ha sido en extensión, y que se trata en general de excavaciones de sondeos.

\section{LA EXCAVACIÓN DEL TÚNEL DE “AGUAS VIVAS": PLANTEA- MIENTO Y METODOLOGÍA}

La intervención que presentamos vino motivada por el proyecto de construcción del túnel de Aguas Vivas (Figura 3), que implicaba un corte transversal de la ciudad medieval desde el barranco de San Antonio hasta el del Alamín, junto al Alcázar. Los sondeos de valoración justificaron la excavación en extensión $\left(800 \mathrm{~m}^{2}\right.$ ) de la parcela de C/ Ingeniero Mariño, localizada junto al Alcázar, y el control del movimiento de tierras en el resto de la superficie afectada 7 . La potente estratificación preservada en el citado solar (Figuras 4 y 5) puso de manifiesto una secuencia de ocupación que abarca desde fase islámica hasta la actualidad, demostrando el potencial arqueológico del subsuelo de Guadalajara (SERRANO, SERRANO y TORRA, 2002).

Por otro lado, y como trabajo arqueológico previo a la ejecución del túnel de Aguas Vivas, se procedió a documentar los restos constructivos localizados en el barranco del Alamín y coincidente con el punto de entronque del túnel y puente diseñados para salvar el barranco. Como resultado de la intervención podemos destacar que se han documentado los restos del último recinto fortificado medieval de la ciudad de Guadalajara, levantado en torno al siglo XIII d. C. y sometido posteriormente a diversas remodelaciones y adaptaciones (TORRA y SERRANO, 2002). La traza del túnel fue modificada, y en la actualidad los citados restos defensivos se han preservado y pueden contemplarse.

\section{A. El método arqueológico}

Antes de detenernos en la descripción de la secuencia debemos insistir en los aspectos metodológicos referidos al proceso y registro de la excavación arqueológica. Los resultados que se presentan son el fruto de la aplicación de un sistema de excavación basado en el método estratigráfico: reconocimiento de la totalidad de las unidades estratigráficas, sean positivas -estratos horizontales, muros, pavimentos- o negativas -fosas, interfacies de destrucción-, horizontales o verticales, de origen natural o artificial, es decir, aquellos elementos susceptibles de ser identificados e individualizados durante

\footnotetext{
7 Las obras de desmonte llevadas a cabo con motivo de la construcción de la Plaza de los Caídos y Avenida del Ejército, explican la ausencia de estratificación arqueológica en este sector de la traza, por lo que el control del movimiento de tierras se consideró suficiente.
} 
el proceso de excavación arqueológica. El estudio de sus relaciones físicas (básicamente, anterioridad o posterioridad), podrá ser representado posteriormente en una matriz o diagrama estratigráfico que represente la secuencia cronológica de la zona excavada.

El sistema de documentación de dichas unidades estratigráficas se basa en la correcta individualización de las mismas, su registro en fichas normalizadas de unidad estratigráfica (en las que se indican sus características físicas, definición, relaciones estratigráficas, composición, interpretación, etc.), la realización de plantas acotadas, secciones acumulativas y documentación fotográfica. Los materiales arqueológicos recuperados en cada unidad estratigráfica individualizada se tratan como un conjunto, siendo de gran importancia las asociaciones de materiales que se presentan; las dataciones de las unidades estratigráficas deben realizarse con los materiales más modernos que aparecen en ellas, ya que en contextos urbanos puede ser habitual la aparición de materiales residuales que, sin una correcta metodología, pueden causar más problemas que aportar soluciones. En palabras del propio E. Harris ( HARRIS, 1991:6364), "El objetivo principal del estudio de la estratificación arqueológica es situar las unidades de estratificación, los estratos y los elementos en su orden secuencial relativo. La secuencia estratigráfica puede y debe construirse sin tener en cuenta los contenidos artefactuales de los estratos".

\section{B. El análisis de la secuencia}

El proceso de periodización se ha realizado a partir, en primer lugar, del diagrama estratigráfico (Figura 6). Una vez obtenida la secuencia se ha procedido al establecimiento de fases y periodos. Su análisis ha permitido reconocer para el periodo islámico cuatro fases de ocupación, que se pueden resumir en la identificación de diferentes grupos de actividades en ocasiones de difícil interpretación: formación de una serie de depósitos, excavación y uso de silos subterráneos de almacenamiento, pozos y cubetas, amortización de la mayor parte de las estructuras de la fase precedente y por último, excavación y uso de fosas de funcionalidad desconocida que implicó la destrucción de parte de las anteriormente mencionadas.

El proceso final de periodización se ha elaborado a partir de la documentación generada por la propia excavación y por el análisis de los materiales contenidos en los diferentes contextos.

El análisis definitivo de los materiales arqueológicos, nos ha permitido asignar dataciones lo más precisas posibles, a las fases previamente establecidas. Como se intentará exponer a lo largo de los siguientes apartados, la búsqueda de indicadores cronológicos o elementos con valor datante no ha sido tarea fácil dada la ausencia de contextos estratigráficos de referencia. Este desconocimiento sobre los conjuntos que pueden llegar a "caracterizar" las diferentes fases de ocupación en el entorno de la zona analizada, ha determinado que la propuesta final de datación pueda resultar novedosa e incluso discutida. En definitiva, las cronologías propuestas se apoyan, fundamentalmente, en el propio análisis de la secuencia estratigráfica.

De especial interés resulta el hallazgo de un conjunto de 37 piezas de cobre recuperado en uno de los estratos que amortizaron un silo subterráneo de almacenamiento. Dada la singularidad de las piezas -los escasos ejemplos conocidos hasta la fecha proceden de trabajos de prospección en Huesca (DOMÍNGUEZ ARRANZ, et alii, 1996), y de la amortización de un pozo en la ciudad de Zaragoza ${ }^{8}$ - su datación ha tenido que realizarse, finalmente, a partir de su posición estratigráfica.

Los únicos elementos con valor datante que presentamos, se reducen al análisis epigráfico

\footnotetext{
8 Agradecemos la colaboración prestada por F. J. Navarro Cabeza, que estudia este tipo de piezas en la región aragonesa, habiendo localizado varios hallazgos. Le animamos a la publicación de los resultados, que con total seguridad aportarán luz a este tipo de conjuntos.
} 
preliminar de una inscripción sobre una orza, y a la documentación de los sistemas decorativos de verde y manganeso y cuerda seca, aparecidos en contextos que se localizan físicamente bajo unidades estratigráficas, cuya cronología es claramente postislámica.

\section{El estudio de los materiales}

El estudio de los materiales cerámicos ha partido de los trabajos de sistematización realizados por Rosselló Bordoy (ROSSELLó, 1991), en los que la denominación tradicional identifica al tiempo, la forma y la función de las piezas, junto a las tipologías de Bazzana (BAZZANA, 1984) o Navarro (NAVARRO, 1991), basadas en la clasificación funcional. Por ello es importante, a la hora de asignar la función, atender al fin específico para el que se hizo la pieza, y no a los usos secundarios que se le pudieron dar. En esta clasificación funcional están presentes los siguientes grupos: vajilla de cocina, almacenaje, servicio de mesa, usos múltiples, usos adicionales, contenedor de fuego, uso arquitectónico y varios. Por otro lado, el estudio tipológico realizado por M. Retuerce de los materiales cerámicos de la Marca Media (RETUERCE, 1998) nos ha permitido, a la hora de abordar nuestro trabajo, conocer o reconocer los diferentes tipos, en qué yacimientos se han encontrado y si se trata de materiales contextualizados o no. Este estudio emplea, fundamentalmente, criterios formales y decorativos, y se encamina a diferenciar las distintas agrupaciones cerámicas durante el periodo Omeya en el marco geográfico de la meseta. Es importante señalar, que la general ausencia de secuencias estratificadas, imposibilita no sólo el establecimiento de cronologías relativas sino, en definitiva, la obtención de conocimientos sobre los ajuares cerámicos representativos de cada fase.

El estudio se ha realizado sobre un total de I I. I 40 fragmentos de cerámica selecta, de los que 4.70 I pertenecen a contextos datados en el periodo islámico. Se han considerado selectos todos aquellos fragmentos que aportaban información relativa a su funcionalidad e identificación tipológica lo más precisa posible. En el apartado descriptivo se han considerado aspectos como acabados, tipo de pasta, decoraciones y técnicas, así como la factura de las piezas. El vidriado se ha considerado un acabado, ya que compartimos la opinión de autores como Rosselló, que estima que se trata de un procedimiento puramente funcional, al facilitar la conservación de los alimentos.

La información procedente del análisis del material no selecto (4.542 fragmentos de los contextos de época islámica) se ha referido, básicamente, a los acabados, presencia/ausencia de decoración y grupos funcionales cuando ha sido posible. Posteriormente se ha procedido a la comparación estadística, con los conjuntos de los materiales selectos, procedente de los mismos contextos $y$ fases.

\section{LA SECUENCIA ESTRATIGRÁFICA}

En esta síntesis destacaremos la descripción del conjunto de materiales arqueológicos de cada una de las fases, dado que su inclusión en contextos estratificados nos ha permitido determinar las características generales de los distintos momentos de ocupación (Figuras 7, 8 y 9).

\section{A. Fase I}

Los primeros indicios de ocupación están representados por una serie de estratos superpuestos de textura arcillosa y compacta cortados por dos silos subterráneos, un pozo y dos fosas de funcionalidad desconocida.

Teniendo en cuenta lo parcial de su documentación poco puede decirse en relación a su formación o uso. Lo más destacable de esta fase es la recuperación de un conjunto de materiales cerámicos estratificados y la constatación de indicios tanto de una presunta actividad textil - dada la localización de dos posibles husos para hilado manual-, como de cierta actividad relacionada con la metalurgia del hierro a escala doméstica, a partir de la recuperación de escorias.

El estudio del conjunto cerámico, realizado sobre un total de 405 fragmentos considera- 
dos selectos, permite caracterizarlo por el predominio de la cerámica a torno, aunque cuenta con fragmentos realizados a mano-torneta (3\%). Las pastas son claras y medias, con cocciones alternantes y en general bien depuradas. En los acabados hay un claro predominio de las cerámicas alisadas, generalmente con engobes pajizos, una mínima representación de la decoración pintada (sólo 2 fragmentos) y una ausencia absoluta de cerámicas vidriadas. En cuanto a la clasificación funcional se documentan hasta 5 grupos, con un repertorio tipológico escaso, siendo los más frecuentes las jarras con arranque de asa en el borde, las jarritas de carena de arista en hombro y cuello cilíndrico, así como las ollas de cuerpo globular con cuello curvo y borde exvasado, bífido y redondeado, o recto con moldura exterior. También se han documentado fragmentos de un alcadafe, un posible ataifor (en cualquier caso, una forma abierta) y un cuello de forma cerrada (iredoma?). Debe destacarse que en todos los tipos las bases son planas. Conviene señalar una pieza cuya tipología recuerda a tipos preislámicos, con paralelos similares en Recópolis o en el Castro de la Coronilla: se trata de una forma cerrada, olla u orza, de base plana y con decoración incisa ondulada. En estos yacimientos es catalogada como perteneciente a la primitiva época islámica -paleoandalusí- fase datada entre el siglo VIII d.C. y la primera mitad del IX d.C (OLMO, 2002).

\section{B. Fase II}

La siguiente evidencia de ocupación es la excavación y uso de silos subterráneos, pozos, fosas de funcionalidad indeterminada y unas cubetas interpretadas en un primer momento como posibles tenerías. Los silos subterráneos de almacenamiento, constituyen la evidencia arqueológica más habitual en el sector central peninsular $y$, como sugieren recientes investigaciones, es probable su relación con grupos segmentarios que conservan la capacidad de almacenamiento familiar de reservas (FERNÁNDEZ UGALDE, 1994; 1997). Aunque el registro arqueológico es escaso, contamos con referencias que localizan silos relacionados con viviendas, en corrales o dependencias anejas, aunque también podría tratarse de áreas de almacenamiento al aire libre.

Se han documentado un total de 27 silos, con predominio de los de formas cilíndricas y piriformes, de paredes alisadas sin revestimiento, directamente excavados en el terreno geológico o cortando estratificación arqueológica. Las capacidades oscilan entre 8 y $40 \mathrm{hl}$., valores que vienen a coincidir con los estimados para silos documentados en otros puntos peninsulares. También se ha localizado un pozo de extracción de agua, de sección circular y pates enfrentados.

Destacamos la documentación de cuatro estructuras semisubterráneas, muy próximas entre sí, excavadas en el terreno geológico, de planta rectangular y esquinas redondeadas. Fueron construidas con hormigón hidráulico y su cara interna presenta un revestimiento, cuya formación podría ser debida a su uso. En un primer momento, se consideró la posibilidad de que estas cubetas se utilizaran en los procesos de curtición. Sin embargo, el análisis químico ${ }^{9}$ del sedimento que recubre las paredes parece descartar su interpretación como tenerías. Así, aunque estas estructuras puedan estar relacionadas con alguna actividad industrial, carecemos de elementos que permitan una identificación segura. Finalmente, hay que señalar la excavación de dos fosas de planta rectangular y esquinas redondeadas, paredes alisadas y base plana. Su interior se encontraba relleno de piedras irregulares de mediano tamaño y bien trabadas; los datos de que disponemos impiden interpretar su posible uso.

Las diferentes estructuras que acabamos de presentar informan sobre espacios urbanos de

\footnotetext{
9 Según el análisis químico del "revestimiento" realizado por Montserrat Gómez y Joan Enrich (Arqueocat, S.L), su estructura laminar o estratificada presenta un $88 \%$ de carbonato cálcico, un 0,25\% de materia orgánica y el resto presumiblemente hierro. La deposición de este carbonato cálcico parece que tiene su origen en la lenta evaporación de agua dura, y no proviene de la carbonatación cálcica de hidróxido cálcico, que es el empleado en las operaciones de calero anteriores a la curtición.
} 
funcionalidad muy diversa, lo que puede sorprender en una extensión tan reducida. Al carecer de indicadores cronológicos que informen sobre el momento en el que se excavaron tanto los silos como el pozo y las cubetas, sólo su posición estratigráfica permite establecer una cronología relativa entre la fase I y la siguiente, fase III, que corresponde a la amortización de las mencionadas estructuras.

\section{Fase III}

Gran parte de los silos, el pozo y cubetas de la fase anterior se amortizaron en un plazo de tiempo relativamente breve, reutilizándose como basureros ${ }^{10}$.

Se ha recuperado un importante conjunto de materiales arqueológicos entre los que destaca la cerámica, el conjunto numismático de 37 piezas de cobre, así como abundantes escorias de hierro. El ajuar cerámico analizado (66I fragmentos selectos y 1.672 no selectos), presenta unas características técnicas y formales similares a las de la fase l: pastas claras y medias bastante depuradas, cocciones alternantes y mixtas y engobes pajizos como acabado habitual de las piezas. Sin embargo, ya no se documenta la factura a mano-torneta, y es ahora cuando aparecen los primeros vidriados, siempre monocromos en verde o melado-amarillento, y en porcentajes muy poco significativos (de 0 a $5 \%$ ).

Los grupos funcionales documentados oscilan entre 4 y 6 , sin un claro predominio de ninguno de ellos; en cuanto a los tipos identificados, el repertorio es semejante al de la fase I: jarras con arranque del asa en el borde; jarritas con claro predominio de las de carena de arista en hombro o de borde con moldura exterior triangular; ollas de borde vuelto, redondeado -moldurado o no-, o bífido (con predominio de las primeras); ataifores (representan un 1\%, igual que en la fase I), redomas y alcadafes. Además, aparecen por vez primera arcaduces, candiles de piquera, tinajas, anafres y atanores. La documentación de estos últimos es interesante, ya que es poco habitual su hallazgo en yacimientos andalusíes " y sugiere una infraestructura hidráulica relativamente desarrollada. Así, todos los tipos identificados son ya claramente islámicos.

Otro hallazgo especialmente interesante ha sido la localización de un conjunto de 37 piezas de cobre, de reducidas dimensiones, formas irregulares (fundamentalmente, redondeadas o rectangulares) y un peso no superior a 1,2 grs ${ }^{12}$. En las leyendas, en epigrafía árabe, aparece: Al-Adl li-llah, "La Justicia es de Dios" en una de sus caras, y "Abdallah b. Muhammad" en la otra. Consideramos conveniente extendernos en el estudio de este conjunto de piezas, dada su singularidad.

Los objetos monetiformes, aparecieron agrupados y adheridos en el fondo de un silo reutilizado como basurero, y posiblemente guardados en un saco de tela, del que quedaban indicios. Su estado de conservación impedía su identificación y lectura. Por ello, fueron sometidos a una restauración ${ }^{13}$ que individualizó las piezas, lo que puede haber provocado pequeñas variaciones metrológicas en el conjunto.

Se trata de un grupo de cospeles de forma irregular, de reducido tamaño y peso, realizados posiblemente en cobre ${ }^{14}$. Las leyendas que presentan aparecen incompletas o fragmenta-

\footnotetext{
10 En este sentido ha sido documentada en gran parte de los asentamientos de la Frontera Media una fase de abandono generalizado de silos datada, a partir de los materiales contenidos en los estratos de amortización, a finales del siglo XI d.C. o principios del XII d. C., y que ha sido vinculado a la extensión de la formación feudal (FERNÁNDEZ UGALDE, 1994; 1997).

II En Madinat al-Zahra de época califal (VALLEJO y ESCUDERO, 1999) y en Murcia datados en el siglo XIII d. C. (NAVARRO, I99I).

12 Su similitud formal con las monedas fraccionarias de época taifa provocó que la primera clasificación realizada a partir de un análisis previo a su restauración, resultara errónea: en una primera presentación de la excavación se proponía una datación para esta fase en plena época taifa (SERRANO y TORRA, 2002), que como veremos ha sido revisada

13 Este trabajo fue realizado por el restaurador F. Gago.

14 Esperamos realizar próximamente un análisis de los componentes metálicos de las piezas.
} 
das, como si hubiesen sido realizadas por un cuño mayor que el cospel. Éstos fueron acuñados, recortados a tijera y limados los bordes, empleando una técnica muy similar a la de las fracciones emitidas durante el periodo taifa, pero diferente y más descuidada que la utilizada para dirhemes y dinares. Otro aspecto interesante de la técnica de fabricación es la pequeña "lengüeta" (borde doblado) que presentan dos de las piezas.

Los cospeles escasamente superan el centímetro, oscilando su tamaño entre $8,3 \mathrm{~mm}$. y I4, I mm, situándose el valor dominante entre II y $12 \mathrm{~mm}$, con un grosor que no excede los $2 \mathrm{~mm}$. El peso medio no supera el gramo $(0,86$ grs.), siendo el valor modal de 0,9 y dominando la frecuencia 0,8-I,I gramos, entre la que se sitúan el 72,95\% del total de las piezas (Figura 10).

La mayor parte presentan únicamente leyenda central, tanto en anverso como en reverso, careciendo de adorno y de orlas, aunque como veremos, existen algunas excepciones.

La leyenda en el anverso (IA-Leyenda I) es:

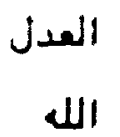

Al-Adl li-llah (La Justicia es de Dios), que aparece de forma completa o parcial, en 10 monedas.

En el reverso (IIA-Leyenda 2) se encuentra la leyenda 'Abdallāh (ibn) Muhammad, en 8 piezas.

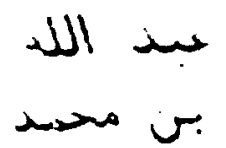

En otros cospeles se distinguen leyendas diferentes; en el caso de uno de ellos: (Ab) d Allah en la primera línea y en la segunda Allah ¿...?; en éste, la leyenda se encuentra enmarcada entre adornos de esquinillas; otro podría tener la leyenda Abdallah en dos líneas, además de orla. El resto del conjunto o presenta letras sueltas o son ilegibles.

Un grupo reducido de piezas muestran adornos, círculos o puntos y grupos de éstos, destacando en una de ellas un adorno central en una de sus áreas (imotivo floral?), que podría recordar a los que aparecen en dirhemes de finales del Emirato Independiente (VIVES, 1893).

La epigrafía de las piezas no es homogénea, presentándose dos grupos: el primero, dominante, que siguiendo a M. Ocaña, podríamos definir como "cúfico arcaico", se caracterizaría por la ausencia de todo ornato y por la absoluta rigidez en torno a la línea base de la escritura (OCAÑA, 1970). En el segundo, la letra álif, presenta unos "ápices" que aparecen a finales del siglo IX d.C. en dirhemes y feluses. Sin embargo, C. Barceló ${ }^{15}$ plantea que los tipos de letra pertenecen a la segunda mitad del siglo $X$ d.C.-primera mitad del siglo XI d.C., aunque en dos de las piezas, considera que existen indicios para situarlas bien entrado el siglo XI d.C.

\section{FaselV}

La última evidencia constatada del periodo islámico, se refiere a la excavación, uso y amortización de fosas irregulares cuya funcionalidad debe de ser de simples basureros y al abandono de pozos y ocasionalmente silos que, a juzgar por la secuencia que presentamos, debió producirse a lo largo del siglo XI d.C. Debemos señalar que el reconocimiento de esta fase, en la que se han considerado conjuntamente la excavación y uso de las estructuras subterráneas y su amortización, se ha realizado a partir de la interpretación como "basurero", asignada a la única fosa documentada en el sector de la excavación con secuencia estratificada para

\footnotetext{
15 Agradecemos a C. Barceló el análisis preliminar realizado sobre la epigrafía de las piezas de cobre.
} 
el periodo islámico. Interpretada esta fosa como basurero, la deposición de su contenido debió de ser inmediata. La similitud del conjunto cerámico de este basurero, con otros procedentes de la amortización de un pozo y varios silos ${ }^{16}$, tanto desde el punto de vista tipológico y funcional como de acabados y técnicas decorativas, ha permitido que incluyamos en esta misma fase los estratos de relleno vinculados al abandono de estas estructuras subterráneas.

Para el estudio del conjunto cerámico de esta fase hemos seleccionado dos contextos que consideramos representativos: por una parte, los estratos de relleno de una fosa irregular, posible basurero, cuya ejecución implicó la destrucción parcial de los estratos que caracterizaban la primera fase de ocupación, así como de uno de los silos amortizados en la fase III; $y$, por otra, un segundo conjunto procedente de un pozo que, aunque carente de relaciones físicas directas, contiene un impresionante lote de piezas prácticamente completas. En ambos conjuntos (2.734 fragmentos selectos) el repertorio es muy similar. Es en este momento cuando se produce la generalización del vidriado, que llega a representar hasta un $24 \%$ del material. El porcentaje mayoritario de cerámicas vidriadas son las monócromas en verde y melado y las meladas con manganeso, y ahora se documentan por primera vez técnicas cómo el verde y manganeso $(7,7 \%)$ y la cuerda seca ${ }^{17}$ en sus dos variedades: total y parcial o de verdugones (7,3\%). También se documentan los primeros vedríos monócromos en negro. Las cerámicas bizcochadas presentan mayoritariamente decoración pintada a trazos en rojo o negro y engobes rojos (55,2 \%), y desaparecen los engobes pajizos característicos de las fases anteriores. En ambos casos las pastas son menos depuradas y la práctica totalidad de las bases son convexas.

En cuanto a los grupos funcionales, están representados prácticamente los mismos que en la fase precedente. Sin embargo, en los tipos se aprecia una importante diversidad y claras diferencias con las fases anteriores: las ollas documentadas en fases I y III son sustituidas, fundamentalmente, por formas con escotadura, bases convexas y paredes muy finas. También son abundantes las ollas de cuello muy corto vertical y labio fino y redondeado, cuerpo globular y base convexa. Aparecen, en un altísimo porcentaje, las jarritas de cuello cilíndrico y cuerpo globular con decoración pintada a trazos, que reemplazan a las jarritas de arista en hombro con engobes claros. Tapaderas, cazuelas, tazas y cantimploras aumentan el repertorio formal conocido; a la vez, cántaros, orzas, ataifores, cuencos, jofainas, botellas o redomas representan un porcentaje mucho más elevado y adoptan gran diversidad de tipos.

Cabe destacar una pieza, posible orza, prácticamente completa, de pastas poco depuradas y engobe exterior rojo que presenta como peculiaridad un graffiti trazado sobre la parte superior del galbo. Aunque el estudio epigráfico definitivo no se ha completado, podemos adelantar que contamos con una posible datación de finales del siglo XI d.C., para la inscripción en la que se aprecian: la expresión Baraka li-llah grabada a modo de letrero, un graffiti central que puede ser una aleya coránica y, por último, unas líneas que parecen indicar intentos caligráficos para reproducir la shahada "no hay más divinidad que Dios" 18 (Láms. I y II).

\footnotetext{
16 El pozo y los silos mencionados se documentaron en el transcurso de los trabajos de seguimiento de las obras del túnel. Aparecieron directamente bajo el asfalto de la Avenida del Ejército por lo que carecen de relaciones estratigráficas.

17 En cuanto al valor de la cuerda seca como indicador cronológico cabe destacar las propuestas de autores como F. Valdés y M. Casamar (CASAMAR y VALDÉS, 1984) que plantean que la generalización de esta técnica se produce durante el periodo Taifa aunque pudiera aceptarse su inicio a finales del Califato. En este sentido, en la Rábita de Guardamar se documentaron 4 fragmentos de cuerda seca parcial, en un contexto datado a finales del siglo X d.C.-principios del XI d.C. (AZUAR, 1990). Contamos también con excepciones como las de Murcia y Málaga donde se han datado fragmentos de cuerda seca en el siglo X d.C. (DOMíNGUEZ BEDMAR, 1987). No obstante, F. Valdés considera que "En términos de cronología, la cuerda seca se documenta con certeza desde comienzos del siglo XI. No existe hoy ningún yacimiento en el que se haya demostrado — y publicado- claramente, por vía estratigráfica, su presencia en el siglo X". Ciertamente, este autor no descarta el inicio de la técnica a finales del siglo X (VALDÉS, et alii, 200 I: 385).

18 Agradecemos a C. Barceló su amabilidad e interés al proporcionarnos unos primeros comentarios acerca de la epigrafía de la pieza, previos al estudio definitivo.
} 
Esta notable diversidad tipológica y, fundamentalmente, el gran desarrollo del vidriado (con la aparición de las técnicas de cuerda seca y de verde y manganeso), junto a la decoración pintada, son las características principales de la fase IV, y coinciden plenamente con la caracterización genérica de la vajilla islámica del siglo XI d.C.

\section{DATACIÓN DE LA SECUENCIA}

La intervención que acabamos de presentar ha permitido reconocer una secuencia estratigráfica en la que se han documentado y excavado contextos islámicos que han aportado un gran número de materiales. Por otro lado, el análisis final de la secuencia se ha concretado en la constatación de diversos grupos de actividades para el periodo islámico, entre los que cabe destacar el almacenamiento subterráneo, pozos de captación de agua, usos industriales o metalurgia del hierro a escala doméstica.

Según el análisis estratigráfico, en todas las áreas excavadas se ha podido documentar que los contextos con materiales claramente atribuibles a la fase III, están cortados por otros que contienen materiales netamente diferenciables, adscribibles a la fase IV, cortada a su vez por una fosa que se rellenó, a juzgar por el análisis de los materiales, en una fase posterior de clara cronología postislámica. En aquellos sectores donde no se han registrado relaciones físicas directas, se constata esa misma diferenciación entre dos repertorios tipológicos y decorativos, que coinciden con los aquí descritos para las fases III y IV, esta última considerada, en principio, de época de Taifas (Figura II).

Ha sido necesaria la búsqueda de indicadores cronológicos fiables que permitiesen asignar dataciones lo más aproximadas posibles a las diferentes fases establecidas a partir del análisis de la secuencia. Sin embargo, la escasez de estudios sobre conjuntos cerámicos debidamente contextualizados -o lo que es lo mismo, procedentes de sitios estratificadosobliga a ser cautos a la hora de asignar cronologías.

\section{A. La cerámica}

Sólo en fechas recientes han comenzado a sentarse las bases para la caracterización de los materiales cerámicos de fases emirales en diversas zonas de la geografía andalusí. Entre las regiones con más registros arqueológicos se encuentran el Sur y Este de al-Andalus, como ponen de manifiesto los resultados presentados en reuniones como la celebrada en Salobreña en 1990, o el importante número de publicaciones generadas sobre el tema. Más recientemente, los trabajos arqueológicos realizados en ciudades como Valencia, Jaén, Mérida o Córdoba están aportando interesantes resultados, sobre todo para las fases paleoandalusíes. Sin embargo, todavía nos encontramos lejos de poder afinar cronologías a partir del registro cerámico para determinar qué objetos son emirales del siglo VIII d.C., del IX d.C. O del primer tercio del $X$ d.C. (ROSSELLÓ, 2002:68). Por el contrario, para la fase de ocupación califal, aunque el registro es más escaso, los lotes datados en el siglo $X$ d.C. resultan muy numerosos, pues la presencia del sistema decorativo en verde y manganeso es utilizada como un claro indicador cronológico.

En la ciudad de Valencia, por ejemplo, varios contextos excavados y datados en fases emirales contienen los primeros materiales vidriados en monócromo verde o melado, siempre asociados a la forma ataifor. Los tipos documentados son ataifores, en su mayoría bizcochados, ollas, cazuelas, tinajas, jarritas, jarras, candiles y arcaduces (PASCUAL, et alii, 1997).

En Marroquíes Bajos (Jaén), el vidriado es significativo a partir del último tercio del siglo IX d.C., datándose los primeros ejemplares documentados a mediados de ese siglo. En plena época califal las piezas vidriadas alcanzan el 61,53\% de los conjuntos analizados. Los primeros vidriados van acompañados de un notable incremento de las cerámicas torneadas, que llegan a representar el $83,65 \%$. Se documentan ollas, redomas, jarros, jarritas, ataifores, tinajas, candiles y tapaderas. En época califal prácticamente ha desaparecido la mano/torneta, el vidriado se generaliza y en cuanto a 
los tipos, el mejor representado es el ataifor, seguido de jarros, jarritas, tinajas, orzas y ollas (PÉREZ, 2003).

En Mérida, las excavaciones realizadas en diversos puntos -Morería, interior de la Alcazaba y área de servicio del anfiteatro- están permitiendo caracterizar los conjuntos emirales con un claro predominio del torno, y el registro de las primeras piezas con vidriado siempre en monocromo verde y asociado exclusivamente a candiles y aceiteras. Las piezas vidriadas son consideradas de importación, y aunque se documentan ejemplares con trazos de pintura en jarras y jarritas, no son tenidas en cuenta como piezas decoradas, dado el carácter profiláctico que se asigna a los trazos. En cuanto al repertorio tipológico, conviven los herederos de la época visigoda-ciertos tipos de ollas y cántaros-, tipos nuevos claramente islámicos -jarros, candiles y arcaducesy unos tipos que son considerados híbridos (ALBA y FEIJOO, 200I).

En el arrabal de Cercadilla (Córdoba) cabe destacar la ausencia de cerámica vidriada en contextos emirales ${ }^{19}$, en los que por otra parte se constata una gran diversidad tipológica, con ollas, jarros, grandes tinajas, lebrillos, tapaderas, cuencos, botellas, candiles, braseros, anafres, platos - precedentes del ataifor-y arcaduces. Salvo los cuencos, el resto de los tipos empiezan a desarrollarse a partir del siglo VIII d.C. Durante la fase califal la cerámica vidriada representa el 14,25\%, las bases son planas o ligeramente convexas, la mayoría de los ataifores carecen de repié, y los anillos de solero sólo se documentan a partir del siglo XI d.C.. La generalización de la cerámica vidriada, con la documentación de los primeros ejemplares en verde y manganeso y cuerda seca (tan sólo dos fragmentos), se encuentra vinculada a los niveles de abandono del barrio califal.

En cualquier caso, no deja de sorprender la documentación de la producción de vidriados locales en Málaga ${ }^{20}$, Almería ${ }^{21}$ o Silves en fechas tan tempranas como el siglo IX d.C. cuando en Córdoba sólo se constata a partir del siglo X d.C. (FUERTES SANTOS, 200 I; VALDÉS, 200I).

Por último, en la zona conocida como Frontera Media son escasos los yacimientos que aporten información de contextos estratificados. Si nos referimos a ámbitos urbanos como Madrid o Toledo, pese al importante número de intervenciones realizadas en su subsuelo, la información es escasa dada la ausencia de secuencias. En Madrid, por ejemplo, los vestigios arqueológicos del periodo islámico se reducen, casi exclusivamente, a la excavación de estructuras subterráneas como silos o pozos y los materiales arqueológicos sólo pueden ser estudiados a partir del análisis de paralelos. Interesa destacar, no obstante, que la mayoría de los materiales recuperados han sido datados en el siglo Xl d.C. a partir de la documentación del verde y manganeso, cuerda seca, vidriados monócromos en negro o melado o con trazos y un repertorio tipológico extenso. Se trata de ajuares típicos del siglo XI d.C. meseteño, lo que corroboran determinados hallazgos numismáticos 22.

Para fases precalifales la información con la que contamos se ciñe a asentamientos como Recópolis (OLMO, 2002), El Turmielo (LÁZARO, 1995), en la revisión de sitios como El Castro de La Coronilla (OLMO, 2002), en materiales procedentes de prospección como los de Olme-

\footnotetext{
19 Los escasos fragmentos recuperados — en estratos siempre en contacto con los califales - así como el reducido número de la muestra, permite interpretarlos como productos importados si se confirma su adscripción emiral (FUERTES SANTOS, 2001:203).

20 Ya desde el siglo IX d.C., se documentan importantes lotes de ataifores vidriados en una amplia gama de melados y decorados con trazos de manganeso, unido a una gran diversidad tipológica: jofainas, tazas, arcaduces, candiles, jarritos, redomas, jarros, marmita, cazuela, alcadafe y tinajas, conviviendo con piezas fabricadas a torno lento (î̃̃IGUEZ y MAYORGA, 1993).

2I En Bayyana se documentan piezas claramente emirales junto a otras vidriadas, incluso en verde y manganeso, en contextos datados en una fase de transición entre el mundo emiral y califal (CASTILLO y MARTíNEZ, 1993).

22 En la intervención realizada en la C/ Cava Baja, 30, de Madrid, se han podido datar determinados conjuntos procedentes del abandono de silos, gracias a la recuperación de un hallazgo numismático no anterior al siglo XII d.C., asociado a ajuares cerámicos como los aquí descritos (FERNÁNDEZ UGALDE, 1996: 25; FERNÁNDEZ UGALDE y SERRANO, 1997: 136).
} 
dilllas (VALIENTE y GARCÍA GELABERT, 1983), Ercávica (ÁLVAREZ DELGADO, 1989) O Navalvillar (CABALLERO ZOREDA, 1989). En general se observa que las fases precalifales cuentan con unos repertorios cerámicos cuyas características más destacables son la ausencia de vidriados y de decoraciones pintadas, unidas a repertorios tipológicos con predominio de formas cerradas (LÁZARO, 1995; OLMO, 2002). En Recopólis (Zorita de los Canes, Guadalajara) y en El Turmielo (Aragoncillo, Guadalajara), por ejemplo, la presencia del vidriado determinará el inicio de la fase califal.

En cuanto a la aparición y difusión del vidriado en la Península, resultan cada vez más numerosos los asentamientos donde se datan contextos con ejemplares vidriados en fechas tan tempranas como mediados del siglo IX d.C. (Málaga, Almería, Jaén o en Mérida), constatándose un incremento gradual a finales de este siglo. Sin embargo, en Córdoba y en los asentamientos mencionados de la Frontera Media los primeros vidriados marcarán el inicio de la fase califal.

Otro indicador cronológico suele ser la pervivencia de tipos de fases precedentes, siempre asociados a formas nuevas que varían según las áreas de estudio.

Según la opinión general, los conjuntos califales se caracterizan por la proliferación del vidriado, la difusión del verde y manganeso y la desaparición de tipos cerámicos no islámicos. Lo califal va a ser datado a partir de la documentación de fragmentos de verde y manganeso en los ajuares cerámicos, no tanto por la presencia de cerámicas vidriadas, ya documentadas en varios asentamientos en fases precalifales aunque en porcentajes, en general, poco representativos ${ }^{23}$. Incluso se están empezando a documentar fragmentos de verde y manganeso en contextos datados en fases anteriores al califato como por ejemplo en Marroquíes Bajos (PÉREZ, 2003:77).
Así, pese a la existencia de claras diferencias regionales, en la mayor parte de las áreas analizadas se está llegando a conclusiones similares. La documentación del vidriado va a permitir datar determinados contextos atendiendo a su representación. En yacimientos con fases paleoandalusíes de ocupación, los materiales cerámicos se caracterizan por la documentación del vidriado, aunque en porcentajes bajos, predominio de bases planas, pervivencia de mano/torneta, así como de tipos claramente preislámicos. Su incremento, junto con la presencia de verde y manganeso, desaparición de tipos preislámicos y ejemplares fabricados a mano/torneta y la sustitución, en varios de los tipos, de las bases planas por convexas, serán considerados como indicadores cronológicos para la fase califal.

\section{B. El conjunto numismático}

Capítulo aparte merece la interpretación del estudio del conjunto numismático, localizado en un estrato de amortización de un silo subterráneo de almacenamiento. Este hallazgo se asocia a los materiales cerámicos descritos para la fase III. Es importante señalar que las piezas que presentamos en este trabajo son escasamente citadas en la bibliografía numismática reciente, y por sus leyendas en general interpretadas como ponderales (Lám. III).

A lo largo del siglo $X X$, la literatura numismática anglosajona se ha interesado por los sistemas metrológicos del Imperio árabe (PETRIE, 1926), catalogando un gran número de ponderales de los periodos Omeya, Abbasí y Tuluní, realizados en la mayor parte de los casos en vidrio (BALOG, 1976). Los investigadores han intentado establecer una relación de estas piezas con las monedas circulantes, el pago de impuestos y las transacciones cotidianas. En 1986 Holland publica un conjunto de 586 ponderales de bronce, procedentes de las ruinas de Cesarea Marítima, en la actual Israel (HOLLAND, 1986). Uno de los aspectos más inte-

23 Debemos excluir los casos de Málaga y Pechina donde la presencia del vidriado en fases emirales llega a alcanzar importantes porcentajes (CASTILLO y MARTíNEZ, 1993; SÁNCHEZ y MAYORGA, 1993). 
resantes de este trabajo es el análisis de los ponderales que, por su bajo peso, no se corresponden con piezas circulantes, considerando el autor que posiblemente mantienen una estrecha relación con recortes de dirham o de dinar, muy frecuentes en el mundo árabe, siendo el tipo de "dinero" empleado para las pequeñas transacciones diarias.

Los recientes trabajos de Album (ALBUM, 1998) e llisch (ILISCH, 1993), están poniendo de manifiesto el desconocimiento que existe sobre las emisiones Omeyas y Abbasidas de cobre, siendo la mayor parte de ellas anónimas: "Like its Umayyad antecedents, copper coinage of the Abbasid period is essentially municipal coinage locally regulated at each mint. Over 100 mints have been reported, but only a portion of these area collectible. An approximate date range is given for each mint, even though many or all coins may be undate. Most bear the name of the local gobernor, but only a few have the name of de Caliph [...]. There is no comprehensive study of the Abbasid perior copper coinage; and many of the date ranges given here are tentative [...]. Large quantities of uncentain Abbasid style fulus are found in Syrian hoards, some vaguely based on the common type of al-Kufa 167, others of various types, usually without mint, date or gobernor. Most are quite tiny, tipically one gram or less" (ALBUM, 1998: 30-31).

En el caso de la Península Ibérica, desde mediados de los años 80, tras la publicación de las láminas de Antonio Delgado por Rodríguez Lorente e Ibrahim, se empieza a describir un grupo de piezas consideradas como "ponderales" (RODRÍGUEZ LORENTE e IBRAHIM, 1985). En principio sus rasgos fundamentales eran la presencia de la leyenda árabe al-Adl, "Justicia" o al-Adl li-llah, "La Justicia es de Dios", asociada en algunas ocasiones a nombres no identificados plenamente. Su forma es, en casi todos los casos, rectangular.

El peso de estas piezas se situaba en lo que se entendía como "dinar legal" emitido duran- te el Califato de Córdoba, como presenta Pellicer en su trabajo de 1988, en el que a través del análisis metrológico y las equivalencias presentes en las fuentes, intenta sistematizar cuáles serían los ponderales empleados en al-Andalus durante el Califato y su posterior influencia o uso en los reinos cristianos del siglo $X \mathrm{l}$ d.C. (PELLICER, 1988).

Pero sin duda, el estudio más importante es el acometido por T. Ibrahim, publicado en la revista Numisma entre 1993-1994, en el que se describen un total de 88 ponderales, la mayor parte de ellos de bronce, siendo minoritarios los tipos de plata (IBRAHIM, 1993; 1994) ${ }^{24}$. Ninguno de ellos tiene procedencia arqueológica clara, señalándose vagamente las provincias de Sevilla y Córdoba, como su lugar de origen. Las leyendas de este tipo de piezas son variadas, aunque las más frecuentes son "Justicia" y "La Justicia es de Dios", junto a otras, que aparecen en un número menor, como por ejemplo la unidad de medida, aleyas coránicas y nombres de personajes. Algunos de estos últimos han sido identificados con funcionarios vinculados a la ceca o, también, como cambistas.

Posteriormente Moll Mercadal publica, en Gaceta Numismática, varios ponderales islámicos de bronce, aparecidos en Mallorca, con forma de prisma rectangular y con la leyenda "La Justicia es de Dios". Se trata de piezas correspondientes a ponderales de dinar y medio dinar, de las que también se desconoce su procedencia exacta y que el autor, siguiendo la epigrafía de las mismas, plantea pueden pertenecer a la taifa de Mallorca y a la dinastía proalmorávide de los Banu Ganiya (MOLL MERCADAL, 1995).

Un conjunto similar al que presentamos en este trabajo, ha sido analizado por C. Lasa en 1996 y 1997 (CABAÑERO y LASA, 1997). Se trata de una colección de 33 piezas, procedentes del entorno de la ciudad de Huesca, sin que se aporten datos más precisos (DOMÍNGUEZ ARRANZ et alii, 1996). De ellas 18 son rectangu-

24 Para la comparación de la metrología de todos los conjuntos, ver CASTRO y SÁNCHEZ (en prensa). 
lares y 15 más o menos circulares, con los cospeles recortados a tijera y los bordes limados. En la leyenda aparece la palabra "Justicia", "Justo", "La Justicia" o "La Justicia de Dios", junto con el nombre propio de Abdallah. El peso medio se sitúa en I,05 gramos, pero la mayoría de las piezas se encuentran en la frecuencia entre 0,80-I, I 7 gramos, con un valor dominante de 0,98 gramos, siendo el resto de las piezas más pesadas, según el autor, un conjunto diferente. Estas son las únicas piezas publicadas hasta el momento, similares a las que presentamos, aunque hay que destacar que las características metrológicas del depósito de Guadalajara, son ligeremente inferiores (Figura 10).

Hemos intentado encontrar similitudes con otras piezas de cobre del periodo islámico. Con un peso similar, existen numerosos feluses del Emirato Independiente, especialmente en la frecuencia 0,6 y 1,2 grs. En cambio, más parecidas en cuanto a su técnica de fabricación, se han estudiado monedas fraccionarias de los reinos de taifas, con un importante lote de piezas de peso y metal similar, aunque de epigrafía diferente (FROCHOSO y MEDINA, 1999).

Metrológicamente es posible una tercera interpretación, si consideramos su identificación como ponderales, cuyo peso se ajusta al |/4 y 1/8 de dinar y aproximadamente al de 1/3 de dirham. Conocemos la emisión de fracciones de dinar por parte del Califato de Córdoba, especialmente en el Norte de África, aunque su presencia en los tesoros es hasta ahora muy poco frecuente, al igual que ocurre con las fracciones de dirham acuñadas por aliados circunstanciales en época del Califa Hisam II. En relación a lo anterior, cabe señalar que, a lo largo del siglo $X$ d.C., se produce en alAndalus la llegada de numerario foráneo, acuñado fundamentalmente por los fatimíes. Sin existir todavía un estudio generalizado a nivel peninsular, y basándonos únicamente en el recientemente publicado por Doménech Belda (DOMÉNECH, 2002) que hace referencia al territorio de Šarq al-Andalus, resulta que, sobre todo durante la segunda mitad del siglo $X$ d.C. y la primera del siglo XI d.C., es frecuente la presencia en los tesoros levantinos de fracciones, fundamentalmente de dirhemes fatimíes, cuyo peso, siguiendo a Balog (BALOG, 1961), se situaría para el cuarto de dirham en 0,75 grs. y para el octavo en 0,30 gramos.

Sin embargo, las piezas que se presentan en este estudio, no han aparecido en ningún caso asociadas a conjuntos fatimíes como los hasta ahora mencionados. Lo mismo ocurre con los tesoros, tanto de época emiral, califal y taifa, en los que se ha localizado y analizado un importante número de fragmentos o recortes de dirhemes, y en los que tampoco se encuentran piezas como las descritas.

Como hemos visto, uno de los rasgos fundamentales de los ponderales hasta ahora catalogados es la presencia constante de la palabra "Justicia" (al-adl) y sus variantes, o de "La justicia es de Dios" (al-Adl li-llah), acepciones que podrían hacer referencia tanto al peso justo o legal de la moneda o el ponderal, como a lo aceptado por la comunidad musulmana, moral o jurídicamente. Sin embargo, no es un término empleado exclusivamente en ponderales, pues existe un número relativamente importante de feluses emitidos durante el periodo Omeya y Abbasí en el Norte de África y Oriente, que hacen mención, bien al concepto moral de la palabra "Justicia", o a la sumisión que el individuo debe ante Allah o el poder constituido. Destacaremos los tipos del catálogo de Walker 727, 728, 729, 922, 923, 939 y 940 (WALKER, 1956). Estas piezas tienen como denominador común haber sido acuñadas siempre en cobre, en el periodo de la primera conquista islámica del Norte de África, si bien hay tipos ya abbasidas como el 940 de Walker. Su cronología abarcaría desde el 100H hasta el I57H, aunque no descartamos su presencia en tipos posteriores. Por último, aparece simplemente la palabra "Justo" en Lavoix 1616, acuñada en Madinat al-Salam (LAVOIX, I887). Sin embargo, a pesar de la relación en sus leyendas, las características morfológicas de estas piezas y las de Guadalajara son muy diferentes.

Junto a la leyenda "Justicia", en los ponderales localizados en la Península es también frecuente la aparición del nombre propio "Abdallah", personaje que hasta ahora no ha sido definitivamente identificado, y que se ha que- 
rido relacionar con prefectos de ceca durante el gobierno de Abd al-Rahman III o con cambistas. No obstante, existen otras posibles interpretaciones, como puede ser la de asociarlo con los gobernadores que aparecen en las fuentes árabes durante el periodo final del emirato y principios del califato, de los que tenemos una información precisa a través del Muqtabis de Ibn Hayyan (VIGUERA y CORRIENTE, 198I). Queda sin explicación, el hecho de que en estas piezas, si se trata de ponderales, no aparezcan otros nombres, pues curiosamente los hasta ahora identificados como tales, abarcan un periodo corto del califato. ¿Es qué no se fabricaron ponderales ni antes ni después?

Como ya se ha señalado, el estudio comparativo tanto de las características formales como funcionales de este tipo de piezas no ha permitido una datación precisa, ya que en ningún caso se han encontrado asociadas con conjuntos monetarios o tesoros plenamente identificados. Sin embargo, lo que diferencia notablemente al conjunto de Aguas Vivas es su aparición en un contexto arqueológico concreto, formando lo que podríamos denominar un depósito o tesoro.

La reutilización de la estructura donde han sido halladas las piezas, como "basurero", parece fuera de toda duda, dado que con el conjunto numismático aparecen fragmentos cerámicos, que en ningún caso corresponden a piezas completas, y también restos de fauna. Por tanto, a partir de los datos arqueológicos, consideramos que se trata de un depósito de piezas que en un determinado momento tuvieron un valor simbólico o material, lo que hizo que fueran agrupadas; la pérdida posterior de este valor, explicaría su aparición en un espacio de vertido.

En cuanto a su funcionalidad, resulta difícil interpretarlas como ponderales, dada su forma irregular ${ }^{25}$. Si se tratase de éstos, tendrían que corresponder necesariamente con fracciones de piezas en circulación, que deberían tener las mismas características metrológicas que el con- junto hallado. A pesar de ello, dichas fracciones no se han encontrado asociadas a estas piezas, ni parece que haya existido un volumen en circulación en época emiral o califal, que permita explicar un conjunto de ponderales exclusivamente ajustado a un peso determinado, al margen de las unidades monetarias que con total seguridad conocemos en circulación, dinares y dirhemes.

Por otra parte, si el fenómeno de recorte de monedas, muy frecuente en la moneda de plata de épocas emiral y califal, estuviera relacionado con las piezas de Guadalajara, implicaría necesariamente la búsqueda de subdivisores al margen de las unidades en circulación, aspecto este último que no está ratificado ni por el análisis de los tesoros estudiados, ni por los contextos arqueológicos.

Ante estas evidencias, optamos por pensar que nos encontramos ante un tipo de moneda fraccionaria de escaso valor, de posible alcance local o regional, desconocida hasta la fecha, y que muy posiblemente realizaría la función exclusiva de numerario para pequeñas transacciones. Otros hallazgos de este tipo de piezas, aún siendo muy limitados, ratifican esta propuesta. Así lo demuestra el conjunto del Ayuntamiento de Huesca, publicado por C. Lasa, aunque también tenemos noticias de la aparición de piezas similares en la ciudad de Zaragoza y en el Valle medio del Ebro aragonés. Éstas siempre se presentan aisladas, o acompañadas de piezas circulantes, que subrayan aún más su funcionalidad como numerario.

\section{UNA PROPUESTA DE DATACIÓN}

Teniendo en cuenta el estudio de los materiales arqueológicos y las dataciones habitualmente consideradas, las fases I, II y III habrían sido comúnmente fechadas en época emiral (dada, fundamentalmente, la ausencia de verde y manganeso), y la fase $\mathrm{IV}$, en época taifa (por la presencia de verde y manganeso y cuerda

25 La pieza número 4 (lám. III) es la única que presenta una forma perfectamente rectangular, y podría ser interpretada como ponderal, aunque su peso coincide con el grueso del conjunto. En una de sus caras presenta una leyenda ilegible y en la otra un adorno. 
seca). Sin embargo, según el análisis estratigráfico que se ha expuesto, y a partir de la segura datación en época de taifas de la fase IV, la fase III y seguramente la II serían atribuibles a época califal. Conviene destacar que se desconocen conjuntos de materiales procedentes de asentamientos meseteños que hayan sido publicados y que presenten características similares a los aquí descritos para la Fase III, con presencia de las primeras cerámicas vidriadas, siempre monocromas y en porcentajes muy bajos, ausencia de decoraciones pintadas y repertorios tipológicos como los descritos.

Así, nuestra propuesta es que contamos con una posible fase emiral, (I), dos fases califales (II y III) y una fase taifa (IV). A continuación se exponen los argumentos que justifican las cronologías propuestas.

La datación taifa de la fase IV se apoya en las características tipológicas descritas para el conjunto de materiales, unida a la generalización del vidriado y a la documentación por vez primera de los sistemas decorativos de verde y manganeso y cuerda seca en sus dos variedades, a la datación preliminar asignada al graffiti trazado sobre una orza, y por último, a la relación física directa con contextos atribuidos a una fase $V$, cuya datación -a partir de los materiales cerámicos- es post-islámica. Esta última fase se caracteriza por la introducción de cerámicas con decoración pintada de finas pinceladas en tipos nuevos, la desaparición de las cerámicas vidriadas bícromas y polícromas, perdurando tan sólo escasos ejemplares en vidriado monocromo en verde o melado, en ataifores de clara tipología islámica.

La datación califal de la fase III a partir del registro cerámico resulta problemática, ya que no responde a lo habitualmente considerado como característico de esta época. Se podría objetar argumentando la posible existencia de un hiato no identificado, que pudiera haber eliminado todo vestigio de época califal. Ante esa posibilidad, que es ciertamente verosímil, ¿cómo explicar que a lo largo de los $200 \mathrm{~m}$ lineales documentados (excavación y seguimiento de la traza del túnel), que representan un corte arqueológico transversal de la ciudad medieval, sólo se registren en el interior de pozos, silos y fosas, materiales como los atribuidos a las fases III o IV? ¿Dónde estaría esa fase intermedia, es decir, la fase califal? ¿Acaso cabe pensar que ese hipotético hiato implicó una transformación tal de la superficie habitada que terminó eliminando totalmente cualquier evidencia de esa fase en el registro arqueológico, incluidas las subterráneas -silos, pozos, etc? ¿No es más fácil suponer que tenemos la fase califal delante, y que hasta ahora hemos sido incapaces de reconocerla?

La bibliografía existente parte del presupuesto de que el rasgo diferenciador de lo califal es precisamente la documentación de vidriados, incluida la difusión desde mediados del siglo $X$ d.C. de las primeras piezas en verde y manganeso. Autores como F. Valdés invalidan la existencia de vidriados en la península antes de estas fechas en Córdoba y su alfoz ${ }^{26}$ y, con la pertinente argumentación, apuntan a que sólo a inicios del XI d.C. se difundirán en el resto de las regiones peninsulares (VALDÉS, 200I).

Ciertamente, sin olvidar las importantes diferencias regionales, ampliamente demostradas, en general se viene sugiriendo que la generalización de la vajilla "típicamente islámica" se produjo a partir de finales del siglo IX d.C., coincidiendo, a decir de los investigadores, con el control del estado Omeya y la ya presuntamente fuerte islamización de la sociedad. Esta islamización implicaría el desarrollo y difusión del vidriado. En nuestro caso, y sin olvidar que los datos manejados proceden de una única excavación, detectamos que la fase III, con o sin vidriado, es ya plenamente islámica en el repertorio formal.

Más problemática resulta la datación de la fase I, dada la similitud de las características de los ajuares cerámicos entre las fases I y III. Tan

\footnotetext{
26 Dato confirmado por las intervenciones arqueológicas realizadas en la ciudad de Córdoba, por ejemplo en Cercadilla (FUERTES y GONZÁLEZ, 1994).
} 
sólo cabe resaltar la ausencia de cerámicas vidriadas, la documentación de escasos fragmentos fabricados a mano-torneta y de una pieza considerada tipológicamente preislámica. Una vez más debemos apoyarnos en su posición estratigráfica, ya que es la relación de anterioridad con varias de las estructuras de la fase posterior, la que nos permite plantear una datación emiral para esta fase, sin posibilidades de mayor precisión.

La identificación tipológica del deposito numismático tampoco ha resultado fácil. Una primera interpretación sería la de que nos encontramos ante un conjunto de piezas de finales del emirato o principios del califato, coincidente con la primera fitna y la desaparición de las emisiones monetarias en plata, junto a una relativa importante acuñación de feluses de cobre, y que se trataría de un conjunto de piezas acuñadas por algún poder local, como se conocen a finales del siglo IX d.C. y principios del $X$ d.C.. La epigrafía, vendría a apoyar esta propuesta, ya que sus rasgos fundamentales (escasa decoración, linealidad, etc.) recuerdan a los toscos feluses con deficiente acuñación, emitidos en un periodo corto de tiempo que coincidió con la desarticulación del poder emiral.

Sin embargo, la ausencia de paralelos de estas piezas, nos obliga a ubicarlas en la posición estratigráfica concreta que aporta la excavación arqueológica. Si las piezas que presentamos pertenecen a la fase III, que se considera de la segunda mitad del siglo $X$ d.C., y que tiene por encima, física y cronológicamente, una fase IV de época taifa directamente superpuesta, no presentándose ningún hiato, debemos considerar el depósito como de la segunda mitad del siglo $X$ d.C., y muy posiblemente de finales de este siglo o principios del XI d.C., lo que sugiere $\mathrm{C}$. Barceló en su análisis preliminar de la epigrafía. La homogeneidad del conjunto impide pensar en un uso muy prolongado de estas piezas, ya que, junto a su similitud física, es destacable la ausencia de intrusiones de piezas de otro tipo. Por todo ello, creemos que el momento de fabricación no puede ser muy anterior al de depósito.

\section{CONCLUSIONES}

Para terminar, creemos que la aportación de este trabajo puede sintetizarse en los siguientes puntos:

La excavación estratigráfica en extensión de una sección de la Guadalajara andalusí ha permitido identificar cuatro fases de época islámica y precisar las características de tres conjuntos cerámicos diferenciados:

- La fase I: conjunto cerámico atribuido a época emiral cuya característica más destacable es la escasa diversidad tipológica, la presencia de algunos ejemplares cuyas características formales coinciden con cerámicas preislámicas, de algún fragmento fabricado a mano/torneta, la ausencia de ejemplares vidriados y de fragmentos con decoración pintada.

- La fase II: excavación y uso de varios tipos de estructuras subterráneas como pozos, silos, cubetas y fosas de funcionalidad desconocida.

- La fase III: conjunto atribuido a la época califal. Bastante similar al anterior en cuanto a la escasa diversidad tipológica, pero en el que ya no se documentan formas no islámicas. Se mantienen los tipos islámicos preexistentes, y se incorporan arcaduces, candiles, atanores o anafres. Se constatan los primeros ejemplares vidriados, siempre monocromos en verde o melado-amarillento, aunque con presencia muy poco significativa.

- La fase IV: de época de taifas, se caracteriza por la gran diversidad funcional y tipológica, la presencia de vidriados en todas sus técnicas (verde y manganeso, cuerda seca parcial y total, etc.) y de decoraciones pintadas en un $55,2 \%$ del total de la cerámica. Se detectan por vez primera muchos de los tipos que comúnmente reconocemos como claramente islámicos, que en la Meseta son fundamentalmente los ataifores, las jarritas de cuerpo globular y cuello cilíndrico con decoración pintada a trazos y las ollas con escotadura en hombro. 
Somos conscientes de que esta caracterización supone una novedad en las clasificaciones al uso. En este sentido, las características de los materiales de las fases I y III, vienen a coincidir con las descritas para otros ámbitos peninsulares que se vienen fechando siempre en momentos anteriores a mediados del siglo $X$ d.C., dada la ausencia de las series vidriadas bícromas y polícromas.

Sin secuencias estratigráficas que apoyen lo contrario, los resultados que hemos presentado permiten plantear que en la Frontera Media la caracterización del periodo califal a partir de los repertorios cerámicos, no pasa por la generalización del vidriado ni por la difusión del verde y manganeso, como parece constatarse en otras regiones a partir de principios y mediados del siglo $X$ d.C. Comunmente se admite que su documentación es un claro síntoma de "islamización", y su ausencia se considera como indicativa de la marginalidad de un territorio. Sin embargo, creemos que en el área que estamos analizando, esa islamización en los ajuares cerámicos ya se había producido durante la fase califal, pero con conjuntos diferentes de los considerados característicos para ese periodo.

De lo anteriormente expuesto se deduce una perdurabilidad de los repertorios cerámicos durante el periodo Omeya, con introducción de nuevos tipos en fase califal, como arcaduces, candiles de piquera, tinajas, anafres, atanores y quizás redomas, desaparición de tipos preislámicos e inexistencia de piezas fabricadas a mano-torneta. Por el contrario en el XI d.C. asistimos a la generalización del vidriado en todas sus variedades, al máximo desarrollo de las decoraciones pintadas, a la introducción de nuevos tipos y a la desaparición de otros: son en definitiva, los ajuares que todos reconocemos claramente como islámicos.

En cuanto a la información aportada por el análisis de las piezas de cobre habría que destacar:
- Estas piezas podrían ser interpretadas, considerando su leyenda, como ponderales, pero sus características físicas, hacen pensar más bien que se trate de cobres de escaso valor, circulantes en la Marca Media y Superior.

- Estos cobres parecen haber sido empleados durante el siglo $X$ d.C., habiéndose producido su depósito a finales de este siglo o principios del Xl. d.C. No será posible concretar el alcance de su circulación y su definitiva cronología en tanto no se produzca un mayor número de hallazgos en estratigrafías arqueológicas, dado que estas piezas carecen de data.

Una consecuencia que puede desprenderse de este primer análisis es que plantea la necesidad de revisar las dataciones del conjunto de yacimientos andalusíes conocidos en la Frontera Media de al-Andalus: si la mayoría de los sitios cartografiados como islámicos presentan una aparente continuidad hasta época taifa dada su identificación a partir de los materiales cerámicos "típicos", ¿dónde estarían los asentamientos de fases iniciales, o los que se abandonaron a finales del Emirato o durante el Califato? Es por ello imprescindible apoyar en secuencias claras las dataciones de asentamientos que se efectúen a partir de los materiales cerámicos. Por otro lado es necesaria la aplicación de estrategias arqueológicas variadas, ya que se pone de manifiesto una "invisibilidad" del registro arqueológico en determinados tipos de asentamientos, fundamentalmente rurales, si partimos exclusivamente del registro cerámico. Recientes trabajos en yacimientos rurales con ocupación desde fases tardoantiguas hasta época emiral, e incluso hasta bien entrado el siglo $X$ d.C. ${ }^{27}$, son un buen ejemplo de cómo con una prospección previa de tipo tradicional jamás se hubiera detectado o reflejado una fase de ocupación islámica. Queda pues patente la dificultad de datar las ocupaciones andalusíes en sus momentos más antiguos.

27 Por ejemplo los yacimientos de Gózquez y Pinto en la Comunidad de Madrid (VIGIL-ESCALERA, 2000). 
En nuestra opinión, esta opacidad del registro arqueológico en la Frontera Media parece demostrada para buena parte de las fases de ocupación islámica, entre otras razones por la falta de reconocimiento de contextos bien datados con ajuares de época pretaifa. Excavaciones extensas en yacimientos con secuencias estratificadas son una de las mejores formas de generar conocimiento arqueológico.

\section{BIBLIOGRAFÍA}

ALBA, M. y FEIJOO S. (200I): "Cerámica emiral de Mérida" GARB-Sitios islámicos del Sur Peninsular, Badajoz, pp. 329-376.

ALBUM, S. (1998): A checklist of Islamic coins, Santa Rosa.

ALVÁREZ DELGADO, Y. (1989): "Cerámicas del siglo IX de Arcávica (Cuenca)", Boletín de Archéologie Medieval, 3, pp. 109-122.

AZUAR, R. (1990): "Una rábita hispanomusulmana del siglo X (Guardamar de Segura, Alicante)", Archeologie Islamique, I,pp. 109-122.

BALOG, P. (1961): "History of the dirhem in Egypt from the Fatimid Conquest until the collapse of the Mamluk Empire 358-922 H./968-I5I7 D.", Revue Numismatique, III, Paris, pp. 109-149.

- (1976): Umayyad, Abbasid and Tulunid Glass Weights and Vessel Stamps, Nueva York.

BARROSO BERMEJO, R.M. y JIMÉNEZ SANZ, P.J. (1992): "Arqueología de la iglesia de los Remedios", III Encuentro de historiadores del Valle del Henares, pp. 93-I01.

BAZZANA, A. (1980): "El yacimiento medieval de Santa Fe de Oliva (Valencia): estudio de su cerámica" Noticiario Arqueológico Hispánico, 18, pp. 257-379.

BERMEJO, J.L. y MUÑÓZ LÓPEZ, K. (1996): "La producción cerámica en el entorno del Henares durante los siglos IX y X", V Encuentro de historiadores del Valle del Henares, pp. 79-85.

BOONE J.L. y BENCO N.L. (1999): "Islamic Settlement in North Africa and the Iberian Peninsula", Annv. Rev. Anthropol, pp. 28, 51- 7I.

CABALLERO ZOREDA, L. (1989): "Cerámicas de “épocas visigoda y postvisigoda' de la provincia de Cáceres, Madrid y Segovia", Boletín de Arqueología Medieval, 3, pp. 75- 107.

CABAÑERO, B. y LASA, C. (1997): "Cultura islámica", Caesaraugusta, no 72-II, Zaragoza, pp. 377-482.
CASAMAR, M. y VALDÉS, F. ( 1984): "Origen y desarrollo de la técnica de la cuerda seca en la Península Ibérica y en el Norte de África durante el siglo XI", Al-Qántara, 5, pp.383-403.

CASTILLO F. y MARTINEZ R. (1993): "Producciones cerámicas en Bayyana", La cerámica altomedieval en el Sur de Al-Andalus. pp. 67-II6.

CASTRO, M. y SÁNCHEZ, A. (en prensa): "Hallazgos numismáticos en Guadalajara: la reciente excavación del túnel de Aguas Vivas", XI Congreso Nacional de Numismática, Zaragoza, Octubre 2002.

CRESPO, M. y CUADRADO, M. (1992): "Arqueología urbana de Guadalajara. Un avance del plano arqueológico de la ciudad", III Encuentro de historiadores del Valle del Henares, pp. 17-32.

CUADRADO, M.A.; CRESPO, M.L.; ARENAS, J.A. (1998): "Primer avance de la excavación arqueológica en el Alcázar de Guadalajara", Actas del VI encuentro de Historiadores del Valle del Henares, Alcalá de Henares, pp. 93- 106.

DOMÉNECH BELDA, C. (2002): "El numerario fatimí en Šarq al-Andalus", Actas X Congreso Nacional de Numismática, Madrid, pp. 48I-490.

DOMÍNGUEZ ARRANZ, F. et alii (1996): El patrimonio numismático del Ayuntamiento de Huesca, Huesca.

DOMÍNGUEZ BEDMAR, M. (1987): "Madinat al-Mariyya. Estudio preliminar de las cerámicas aparecidas en sus atarazanas", II Congreso de Arqueología Medieval Española, vol. Il, pp. 568-577.

FERNÁNDEZ UGALDE, A. (1994): "El fenómeno del relleno de silos y la implantación del feudalismo en Madrid y en el reino de Toledo", Actas del IV Congreso Medieval de Arqueología, vol. III, Alicante, pp. 61 I-617.

- (1996): "Excavaciones en la Cava Baja, 38, 32 y 30 de Madrid: muralla del 'segundo recinto' y vestigios del poblamiento medieval", Reunión de arqueología madrileña, pp.21-29.

- (1997): "El almacenamiento subterráneo y la conquista feudal en la península ibérica: aportaciones de la arqueología", Medieval Europe Brugge, vol. 6, pp. 283-289.

- (200I): "Sobre la identificación arqueológica de los asentamientos beréberes en la Marca Media de al-Andalus", La islamización de la Extremadura romana. Cuadernos emeritenses, $n^{\circ} .17$, pp.139-190.

FERNÁNDEZ UGALDE, A. y SERRANO HERRERO, E. (1997): "Las murallas de Madrid: excavaciones recientes y apuntes para su evolución", Estudios de prehistoria y arqueología madrileñas, 10, pp.|3|-|5|.

FROCHOSO, R. (200 I): Los feluses de al-Andalus, Córdoba.

FROCHOSO, R. y MEDINA, A. (1999): "Las monedas fraccionarias de los reinos de taifas", Numisma, n² 242, Madrid, pp. 81-101. 
FUERTES SANTOS, M. y GONZÁLEZ VIRSEDA, M. (1994): "Nuevos materiales cerámicos emirales de Cercadilla (Córdoba): ensayo tipológico", Anales de Arqueología Cordobesa, 5, pp. 277-30I.

FUERTES SANTOS, M. C. (200 I): La cerámica califal del yacimiento de Cercadilla, Córdoba.

GARCÍA SOTO, E. y FERRERO ROS, S. (2002), "Excavaciones en el despoblado musulmán de Los Casares (Riba de Saelices, Guadalajara): Campañas de 1998, 1999 y 2000", Actas del Primer Simposio de Arqueología de Guadalajara. Madrid, pp. 5। 3-530.

IBRAHIM, T. (1993): "Ponderales andalusíes", Numisma, $n^{\circ}$ 233, Madrid, pp. 39-68.

-(1994): "Ponderales andalusíes (Anexo)", Numisma, $\mathrm{n}^{\circ}$ 234, Madrid, pp. 61-72.

ILISCH, L., ed. (1993): Sylloge numorum arabicorum. Tübingen. Palästina : IV a Bilad as-Sam I, Tübingen.

INIIGUEZ SÁNCHEZ Ma C. y MAYORGA MAYORGA J.F. (1993): "Un alfar emiral en Málaga”, La cerámica altomedieval en el Sur de Al- Andalus, pp. 117-138.

HARRIS, E. (199|): Principios de estratigrafía arqueológica, Barcelona.

HOLLAND, L. (1986): "Islamic Bronze weights from Caesarea Maritima" ANSMN, no 31, Nueva York, pp. |7|-20|, + 6 láminas.

LÁZARO, I. (1995): "Los materiales islámicos de "El Turmielo" (Aragoncillo, Guadalajara)", Kalathos, I3-14, pp. |33-|4|.

LAVOIX, M.H. (I887): Catalogue des monnaeis musulmanes de la Bibliothèque Nationale, Paris.

MALPICA, A. Ed. (1993): Primer Encuentro de Arqueología y Patrimonio: La cerámica altomedieval en el sur de alAndalus, Granada.

MANZANO, E. (|99|): La frontera de al-Andalus en época de los omeyas, Madrid.

MÁRTINEZ LILLO, S. y SERRANO PIEDECASAS, L. (1998): "El poblamiento andalusí en al-tagr al-awsat (Marca Media). El mundo omeya", en Malpica, A. (ed.) Castillos y territorio en al-Andalus, Granada, pp. 7I-II5.

MAZZOLI-GUINTARD, C. (2000): Ciudades de al-Andalus: España y Portugal en la época musulmana (siglos VIII-XV), Granada.

MOLL MERCADAL, B. (1995): "Ponderales islámicos de bronce hallados en Menorca", Gaceta Numismática, n I18, Barcelona, pp. 5-7.

NAVARRO, J. (1991): Una casa islámica en Murcia, Murcia.

OCAÑA JIMÉNEZ, M. (1970): El cúfico hispano y su evolución, Madrid.
OLMO ENCISO, L. (2002): "Arqueología medieval en Guadalajara. Un estado de la cuestión", Actas del Primer Simposio de Arqueología en Guadalajara, tomo II, Madrid, pp. 467-499.

PASCUAL, P. et alii (1997): "València i el seu territori: contets ceràmics de la fi de la romanitat a la fi del califat (270-1031)", Contextos ceràmics d'època romana tardana i de l'alta edat mitjana (Segles IV-X), Arqueomediterrànea, 2, Barcelona, pp. 179-202.

PAVÓN MALDONADO, B. (1984): Guadalajara medieval. Arte y Arqueología árabe y mudéjar, Madrid.

PELLICER, J. (1988): Al-Andalus. Las fuentes y la numismática (síntesis cronológico-metrológica de las acuñaciones del Califato de Córdoba), Barcelona.

PÉREZ ALVARADO, S. (2003): Un indicador arqueológico del proceso de islamización: las cerámicas omeyas de Marroquíes Bajos (Jaén), Jaén.

PETRIE, W.M.F. (1926): Ancients Weights and Measures, Londres.

PRADILLO Y ESTEBAN, P. (|99|): "El desarrollo histórico del casco antiguo de Guadalajara", Wad al-Hayara, I8, pp. 299-329.

PRESAS VÍAS, M. (2002): "Trabajos arqueológicos de apoyo a la restauración en la iglesia de Santa María de la Fuente, concatedral de Guadalajara", Primer Simposio de Arqueología en Guadalajara, tomo II, Madrid, pp.739-746.

RETUERCE, M. (1998): La cerámica andalusí de la Meseta, Madrid.

RODRÍGUEZ LORENTE, J.J y IBRAHIM, T. (1985): Láminas inéditas de D. Antonio Delgado, Madrid.

ROSSELLÓ BORDOY, G. (1991): El nombre de las cosas en al-Andalus: una propuesta de terminología cerámica, Palma de Mallorca.

- (2002): "Cerámica califal, cerámicas periféricas. Una aproximación a la cerámica andalusí de los siglos X-Xl", Al-Andalus Omeya, Córdoba, pp. 67-104.

RUIZ QUINTANAR, L. (2002): "La fragmentación de moneda en época Omeya", Actas X Congreso Nacional de Numismática, Madrid, pp. 533-542.

SERRANO, E. y TORRA. M. (2002): "La secuencia islámica en el solar de C/ Ingeniero Mariño, 27 (Guadalajara)", Primer Simposio de Arqueología en Guadalajara, tomo II, Madrid, pp. 557-567.

- (en prensa): "Vivir en la frontera: aportaciones de la arqueología en Guadalajara (siglos X y XI)" Congreso Internacional Almanzory su época, celebrado en Córdoba entre el 14-18 de Octubre de 2002.

SERRANO, E., SERRANO N. y TORRA. M. (2002): "Actuaciones arqueológicas: el túnel de "Aguas Vivas" (Guadalajara)", Primer Simposio de Arqueología en Guadalajara, tomo II, Madrid, pp. 7|3-723. 
TORRA, E. Y SERRANO, E. (2002): "Nuevos restos de muralla en el Barranco del Alamín (Guadalajara)", Primer Simposio de Arqueología en Guadalajara, tomo II, Madrid, pp. 779-786.

TORRES BALBÁS, L. (1940): "El puente de Guadalajara", Al-Andalus V, pp. 449-458.

VALDÉS, F. (200I): "Acerca de la islamización de Extremadura", La islamización de la Extremadura romana. Cuadernos emeritenses 17, pp. 335-368.

VALDÉS, F. et alii. (200I): "La cerámica andalusí de la ciudad de Badajoz. Primer periodo (siglos IX-XII), según los trabajos en el antiguo Hospital Militar y en el área del aparcamiento de la C/ Montesinos", Garb: sitios islámicos del Sur peninsular, pp. 377-399.

VALIENTE MALLA, J. y GARCÍA-GELABERT, M.P. (1983): "La Cueva Harzal de Olmedillas. Resultados de una prospección," Wad al-Hayara, I0, pp. 7-24.
VALLEJO, A. y ESCUDERO, J. (1999): “Aportaciones para una tipología de la cerámica común califal de Madinat alZahra", Arqueología y territorio medieval, 6, pp. 142.

VIGIL-ESCALERA, A. (2000): "Cabañas de época visigoda: evidencias arqueológicas del sur de Madrid. Tipología, elementos de datación y discusión" Archivo Español de Arqueología, 73, pp. 223-252.

VIGUERA, Ma J. y CORRIENTE, F. (I98I): Ibn Hayyan de Córdoba. Crónica del califa Abdarrahman III an-Nasir entre los años 912 y 942 (al-Muqtabis V), Zaragoza.

VIVES Y ESCUDERO, A. ( 1893$)$ : Monedas de las dinastías arábigo-españolas, Madrid.

WALKER, J. (1956): A catalogue of the Muhammadan coins in the British Museum, vol. II, Londres. 


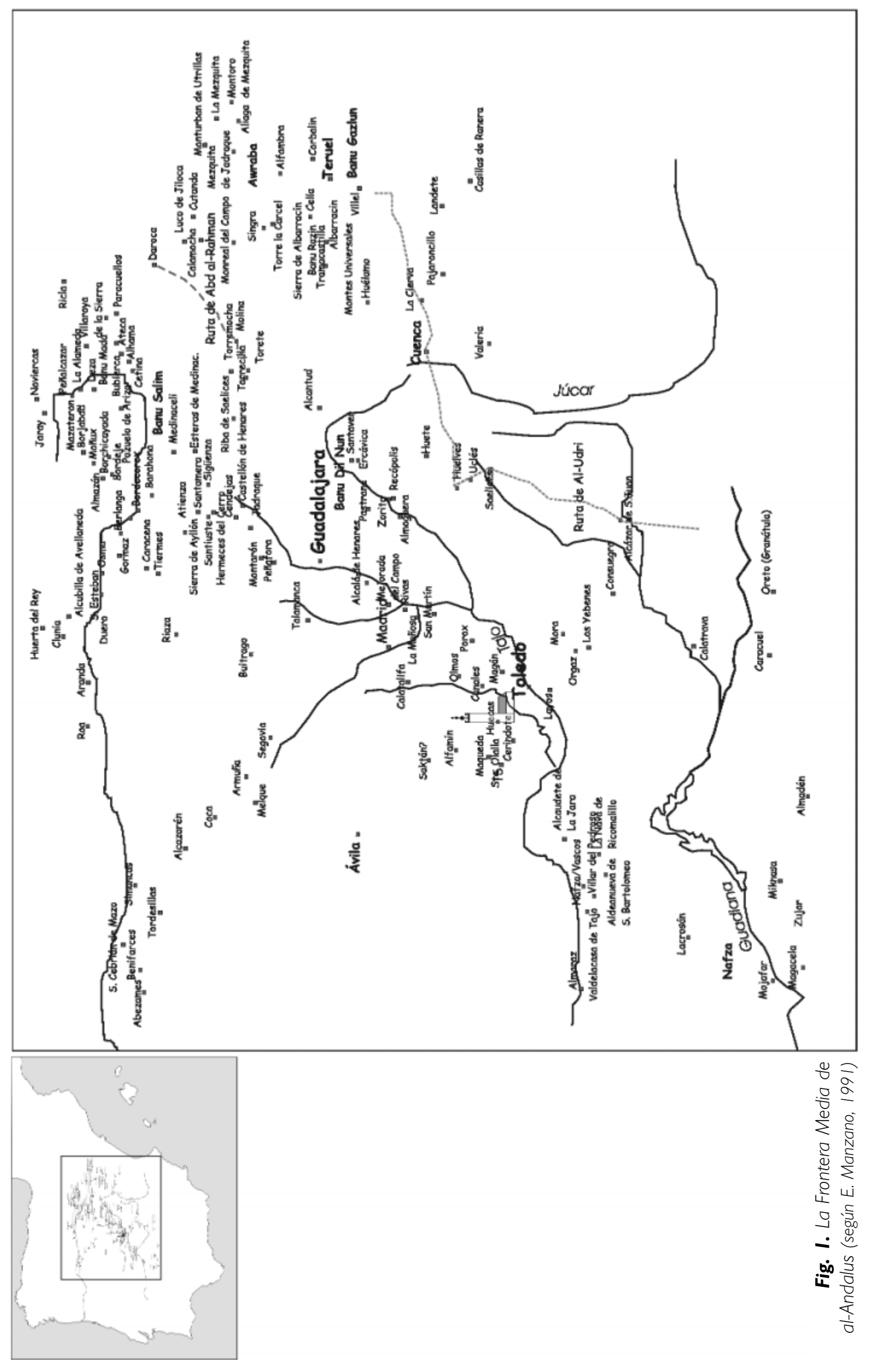




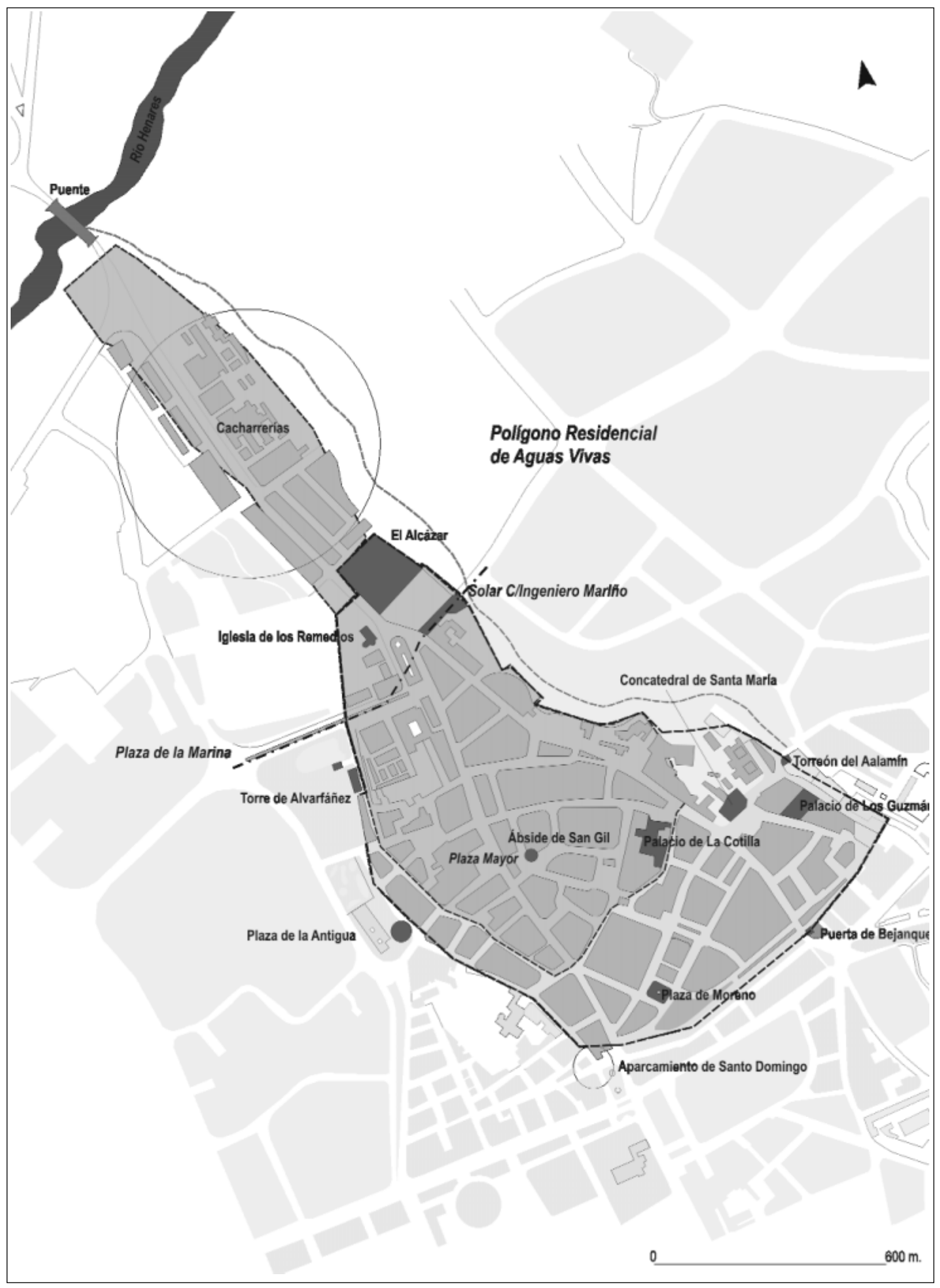

Fig. 2. La ciudad de Guadalajara. Intervenciones arqueológicas 


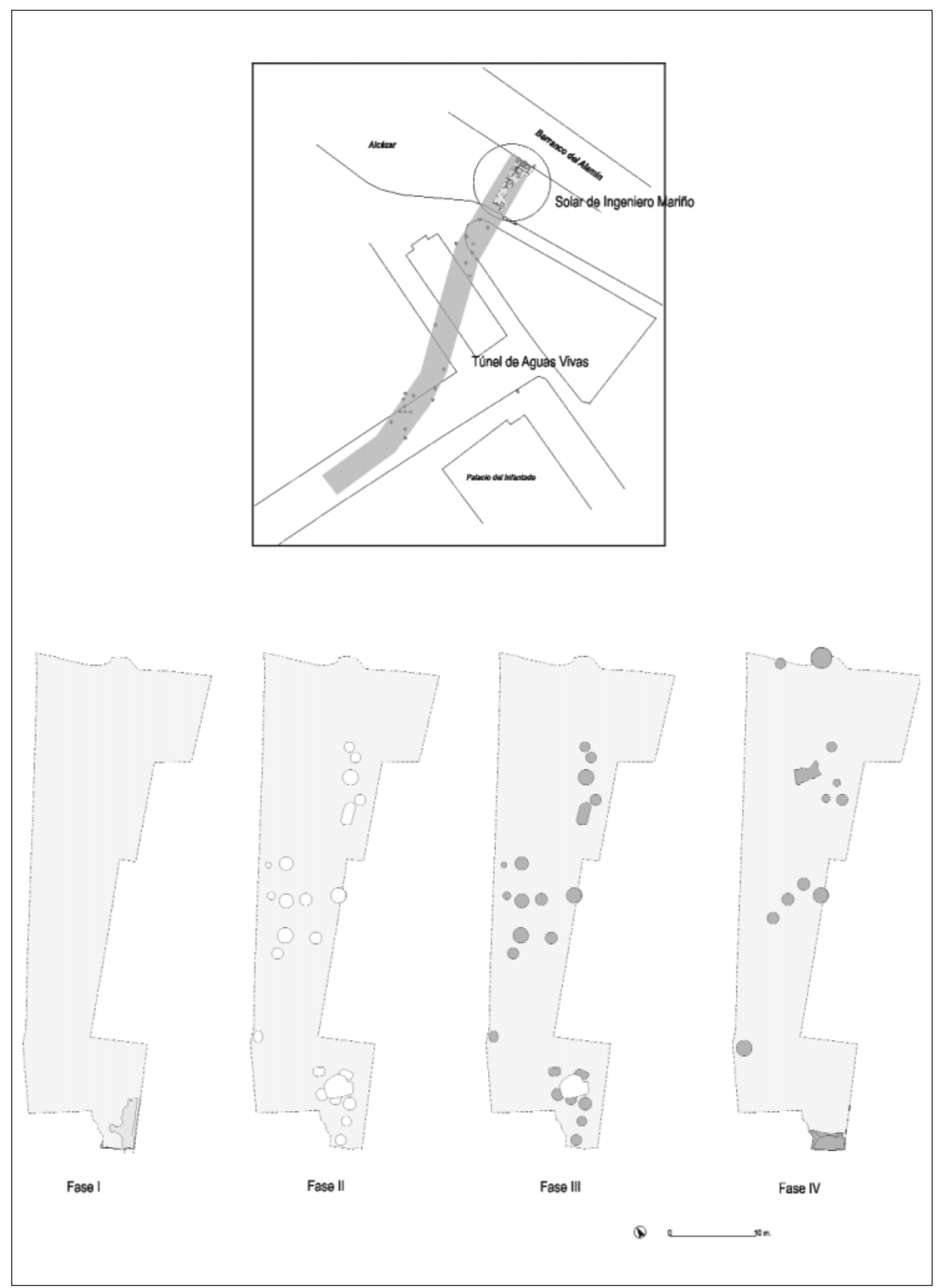

Fig. 3. Túnel de Aguas Vivas: superficie afectada por la intervención arqueológica. Plantas de fase del periodo islámico del solar de Ingeniero Mariño 


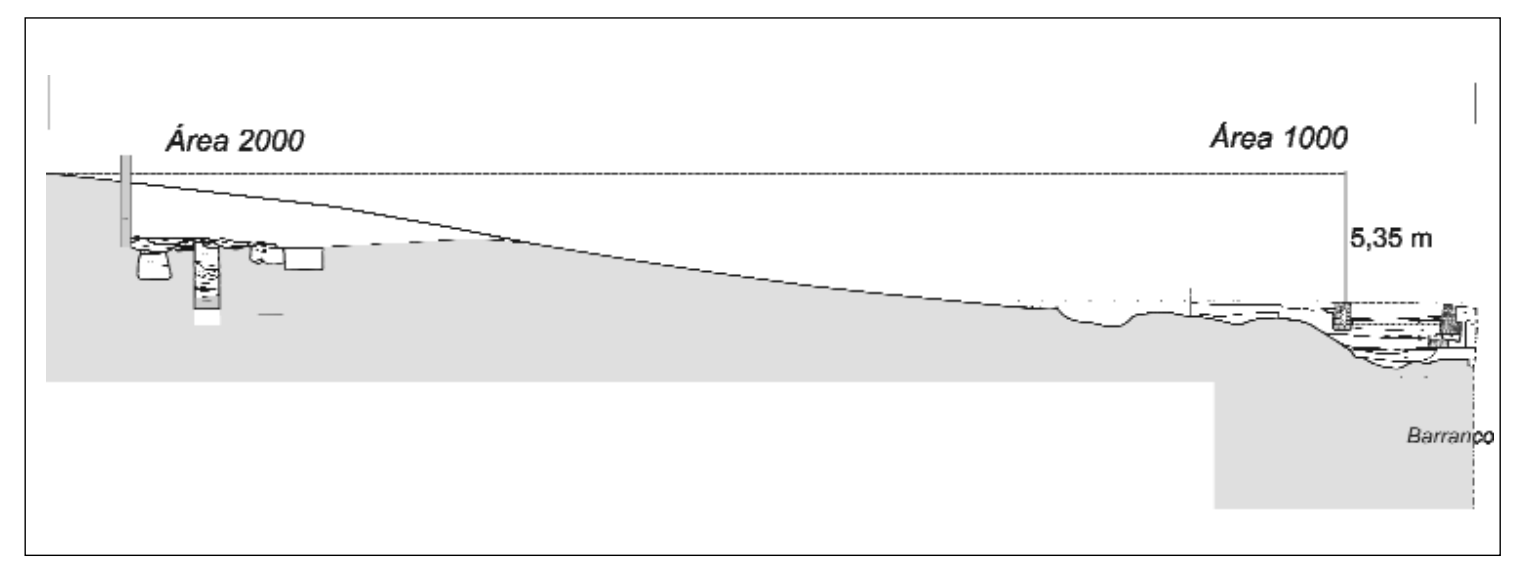

Fig. 4. Sección longitudinal de la parcela de Cl Ingeniero Mariño

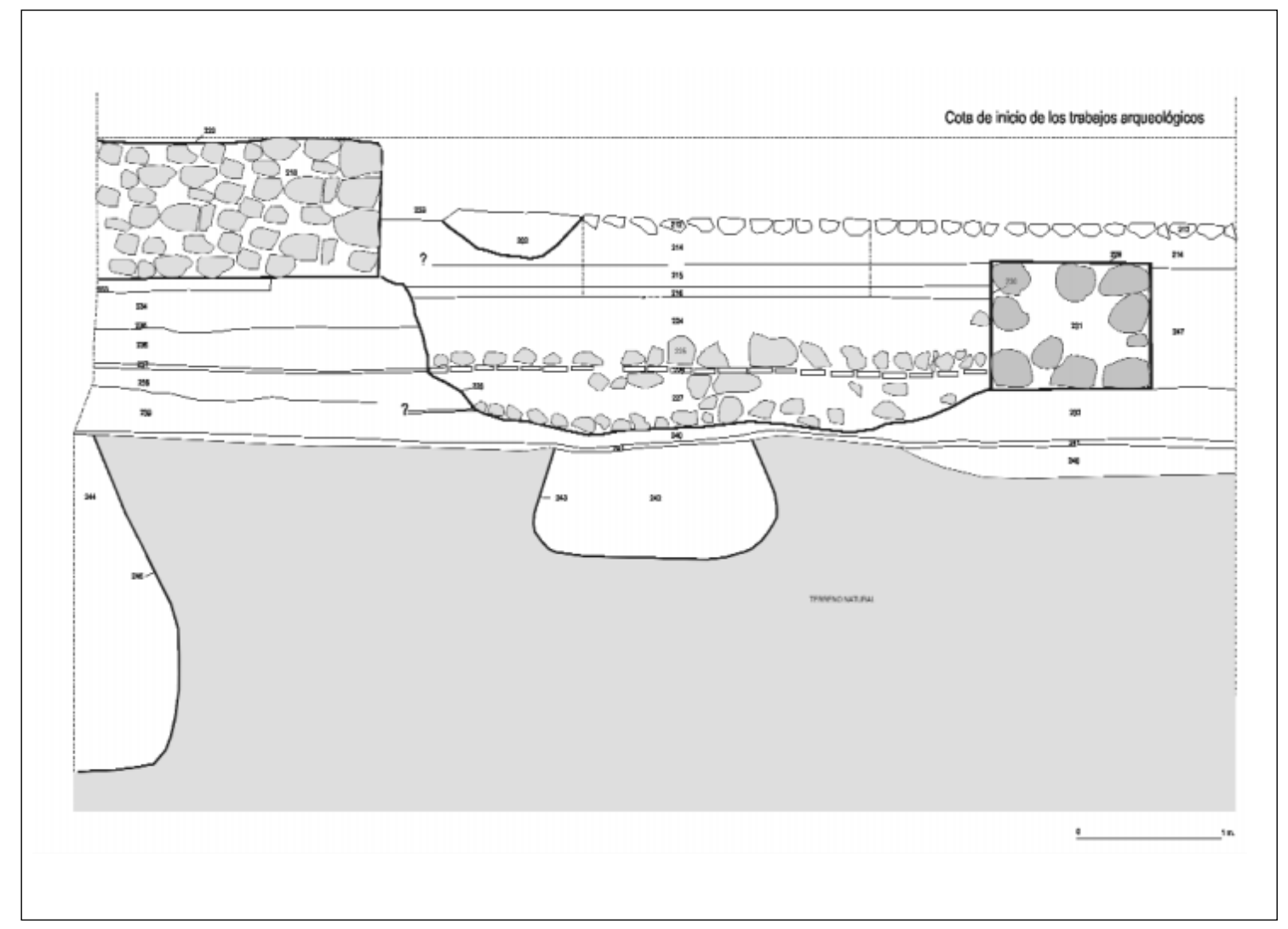

Fig. 5. Estratificación arqueológica documentada desde el Barranco del Alamin en el solar de Cl Ingeniero Mariño (Área 1000) 


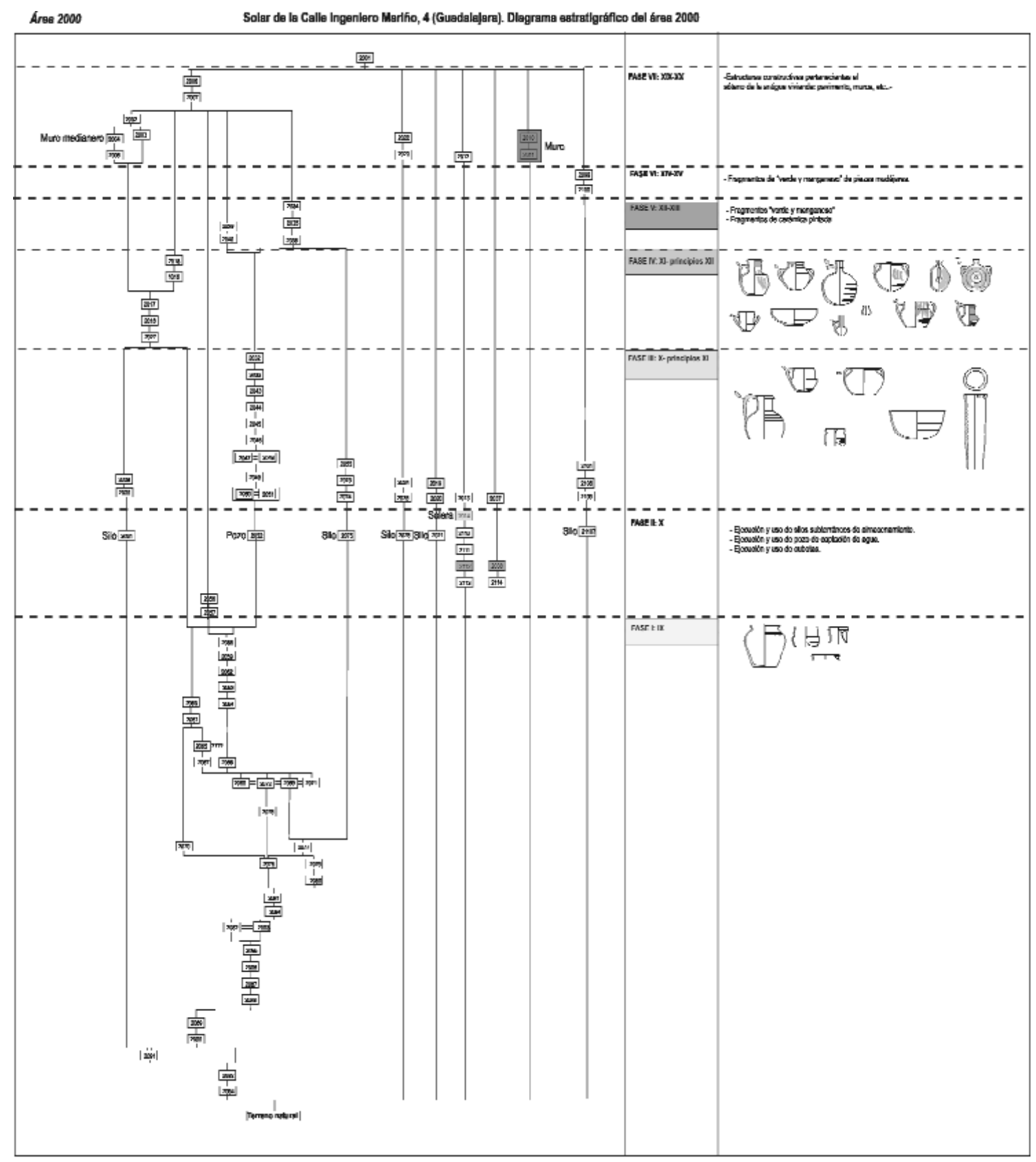

Fig. 6. La secuencia estratigráfica (Área 2000) 
FASE I

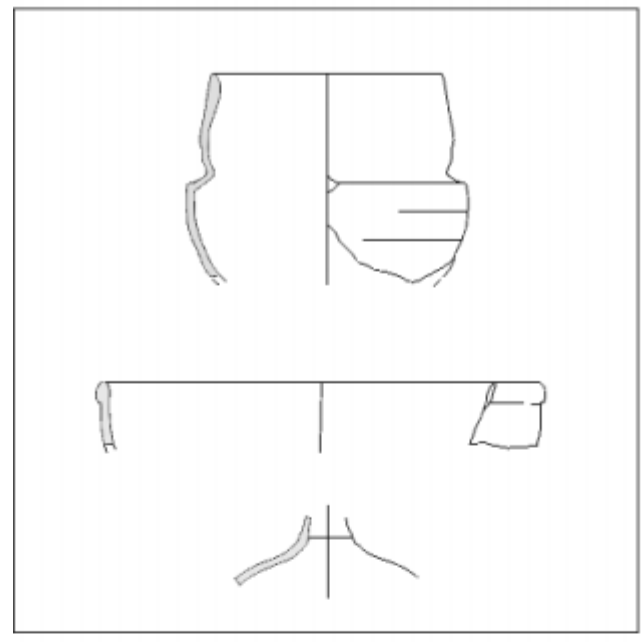

FASE III

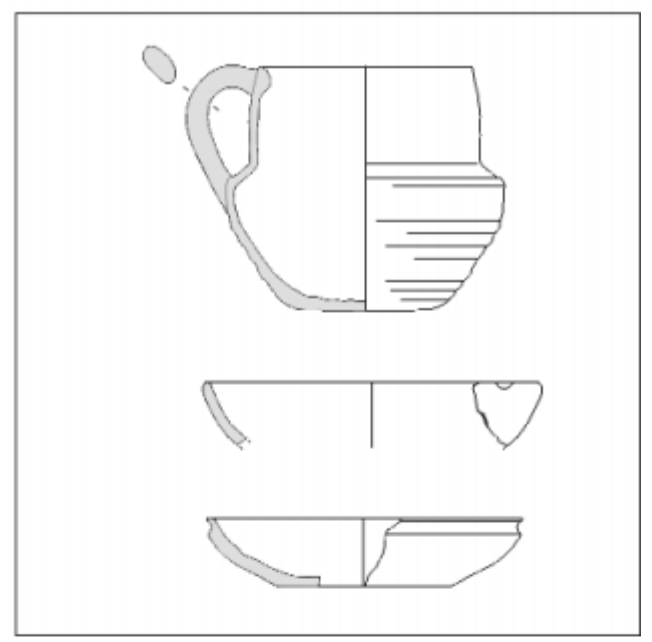

FASE IV

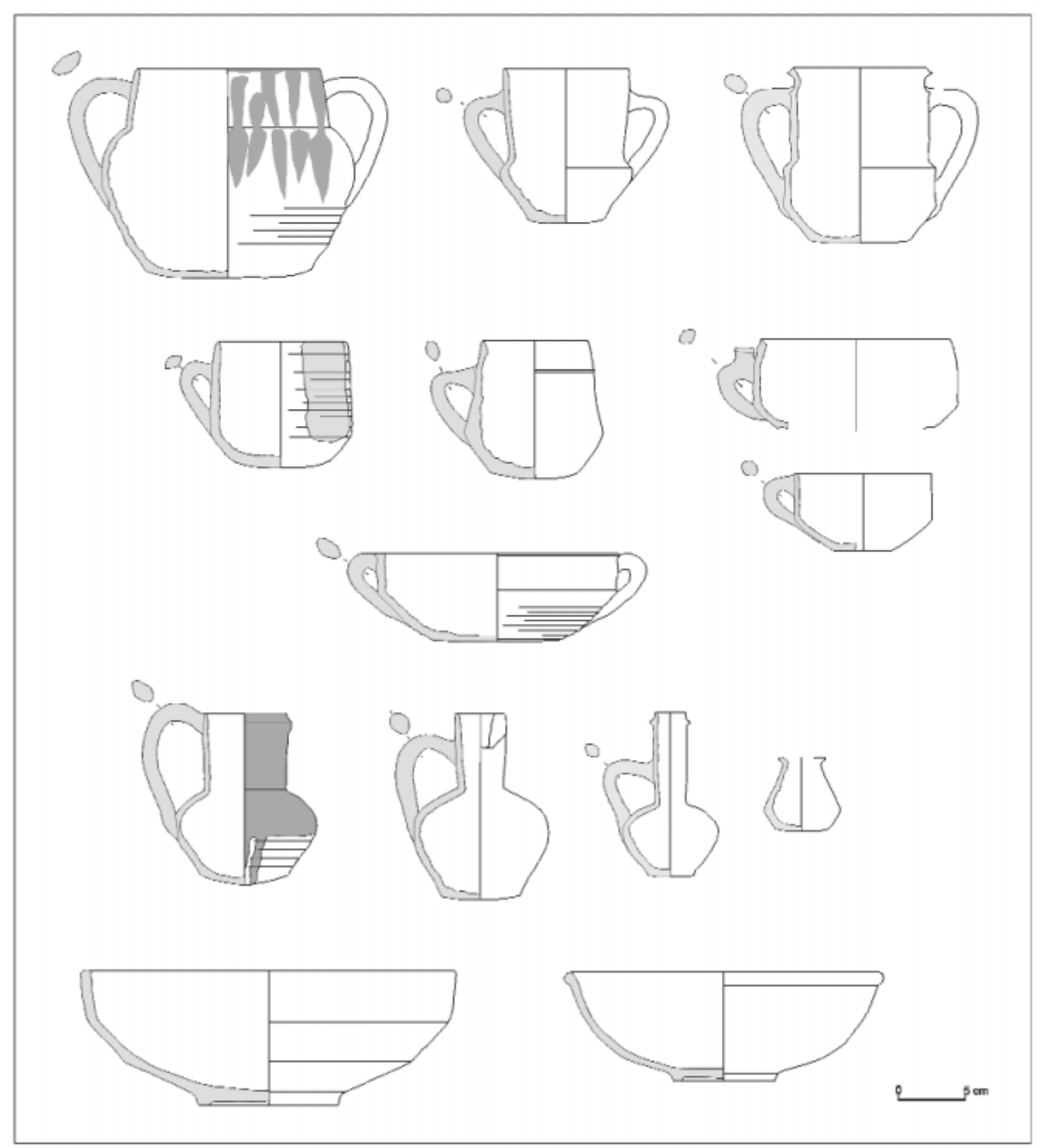

Fig. 7. Vajilla de servicio de mesa 

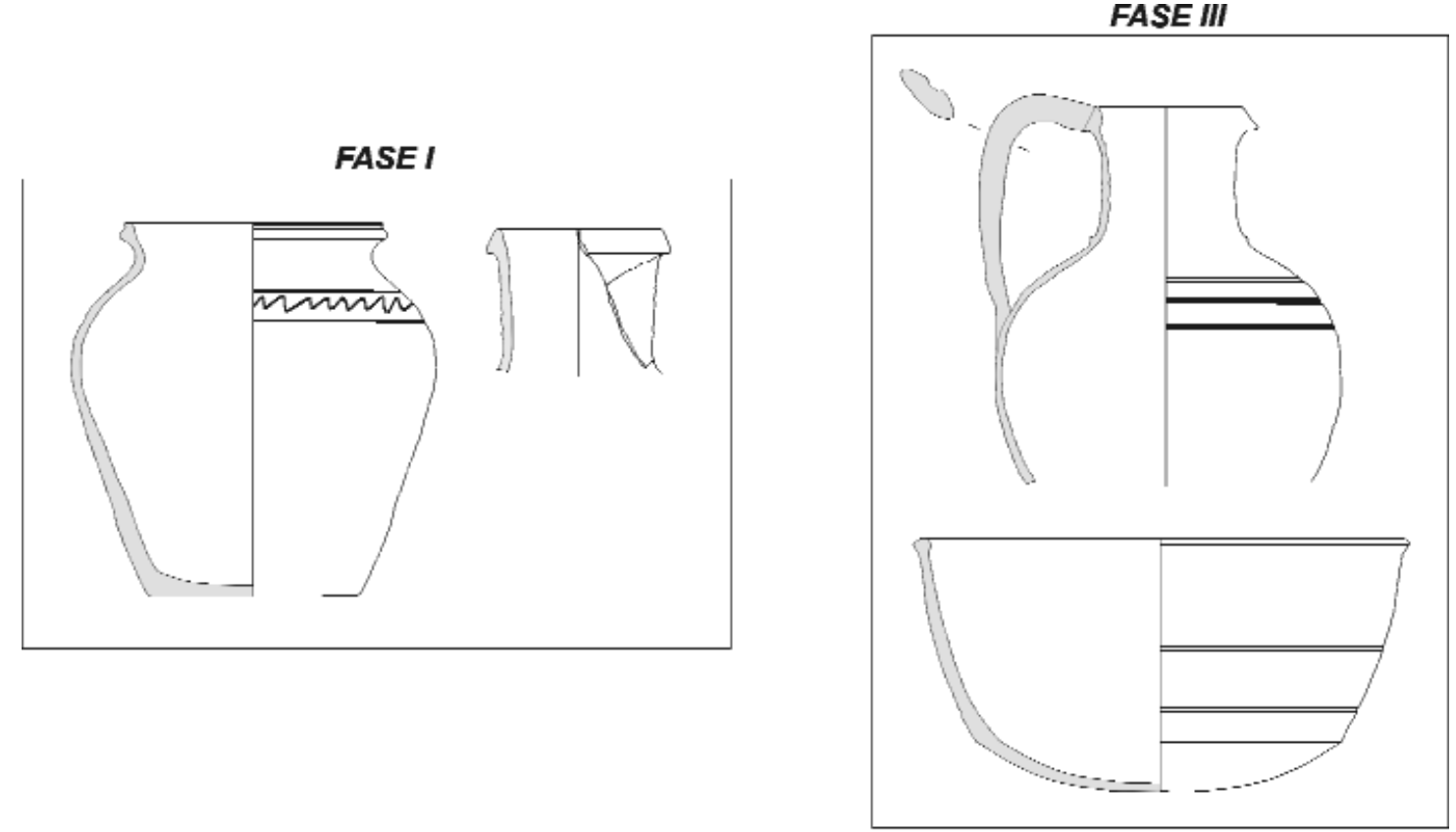

FASE IV

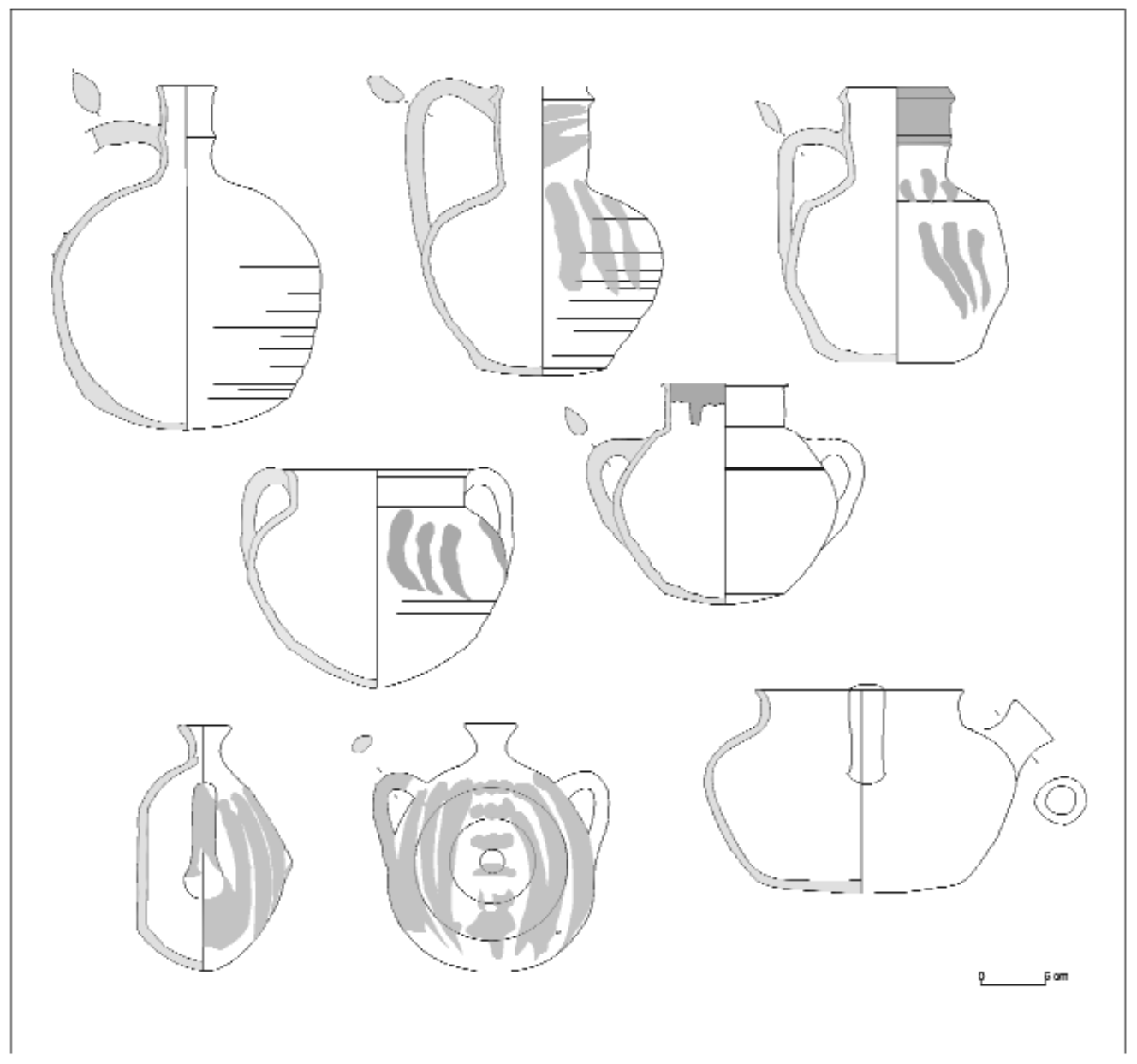

Fig. 8. Vajilla de almacenaje, transporte y conservación 


\section{FASE I}

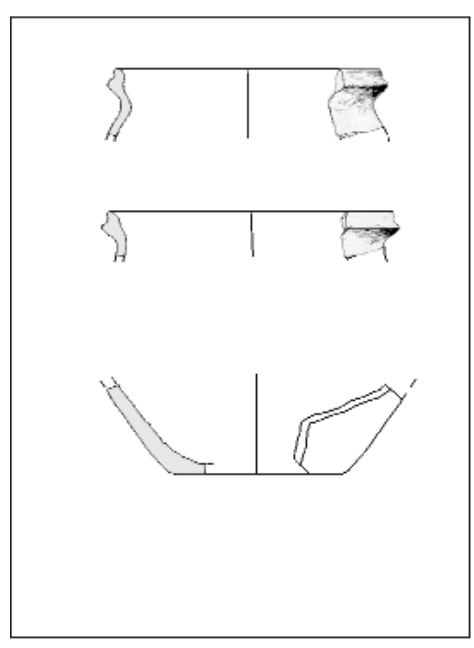

FASE III

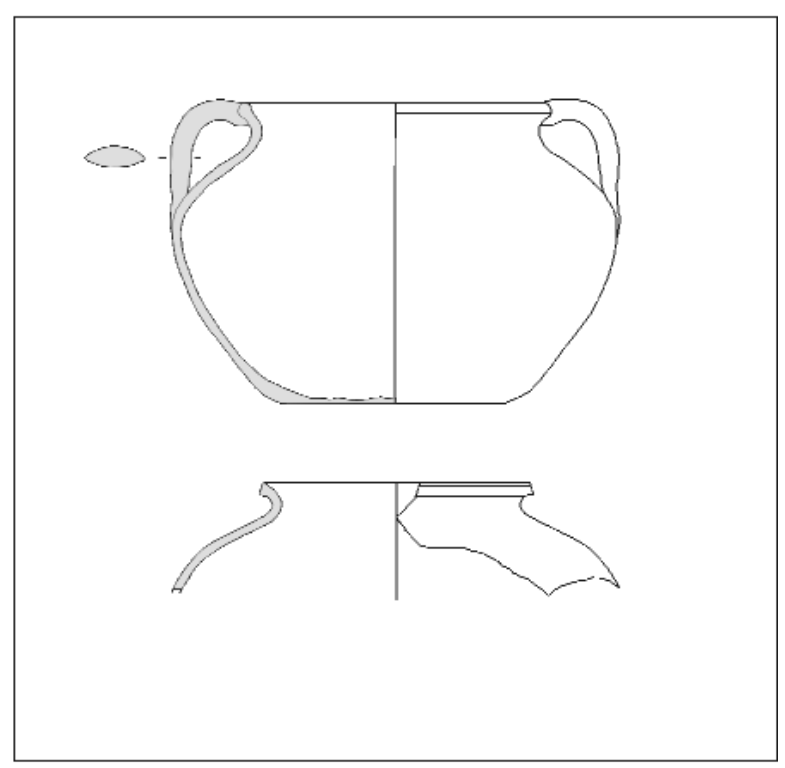

FASE IV

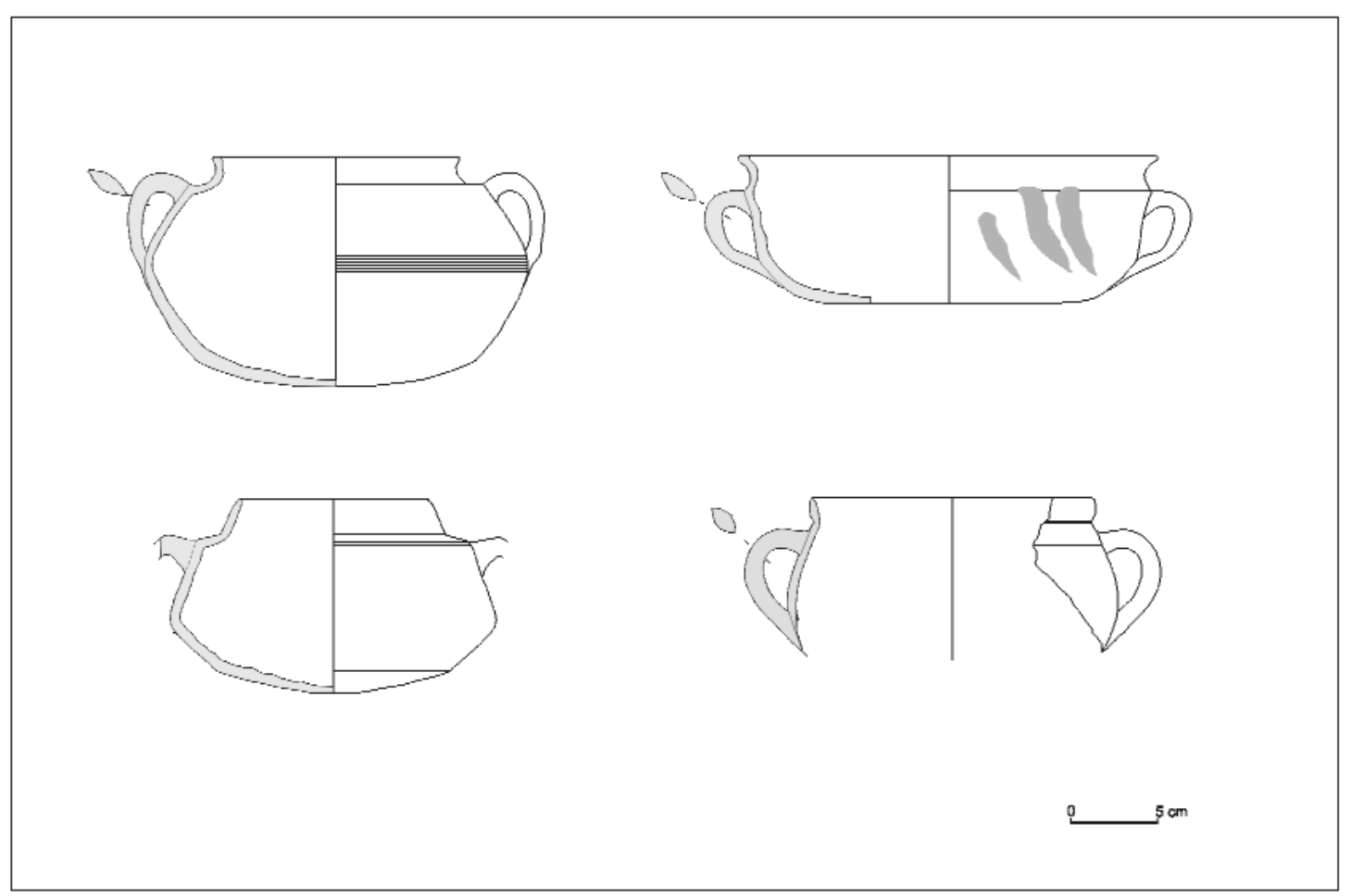

Fig. 9. Vajilla de cocina 


\section{Frecuencia de pesos}

Valor-peso
\begin{tabular}{|l|ll|}
\hline Valor & $\mathbf{N}^{\mathbf{0}}$ piezas \\
\hline 1,2 & 2 & $(5,40 \%)$ \\
\hline 1,1 & 6 & $(16,21 \%)$ \\
\hline 1 & 7 & $(18,91 \%)$ \\
\hline 0,9 & 8 & $(21,62 \%)$ \\
\hline 0,8 & 6 & $(16,21 \%)$ \\
\hline 0,7 & 4 & $(10,81 \%)$ \\
\hline 0,6 & 2 & $(5,40 \%)$ \\
\hline 0,3 & 2 & $(5,40 \%)$ \\
\hline
\end{tabular}

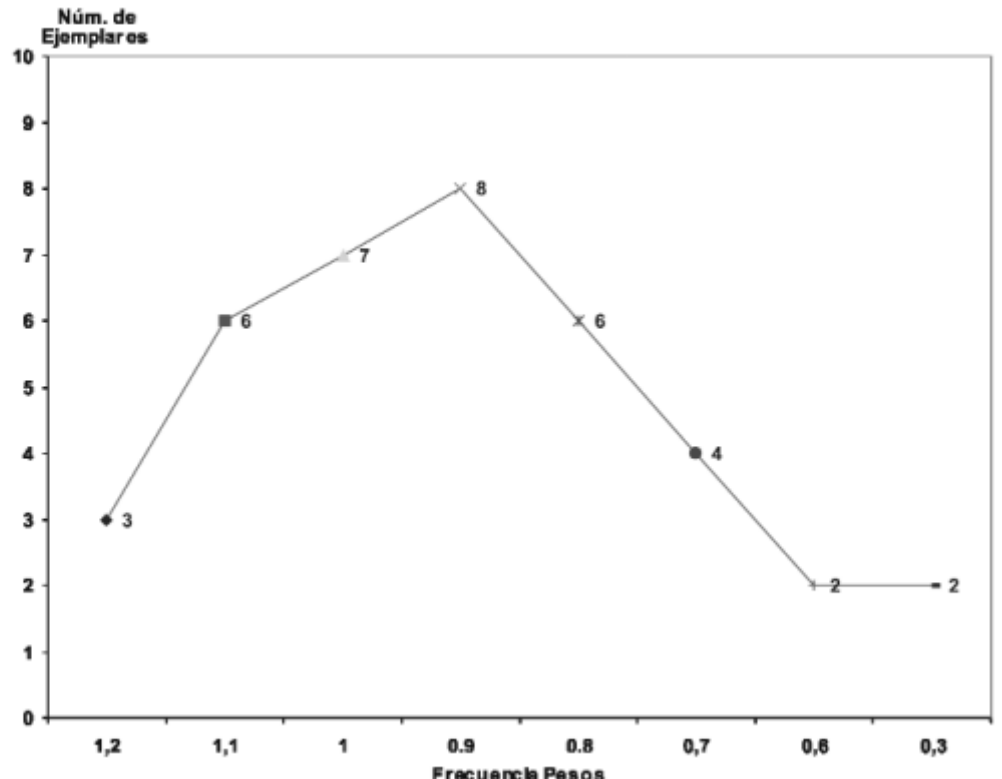

Fig. IOa. Tabla y gráfico de la frecuencia de pesos del conjunto de Aguas Vivas (superior).

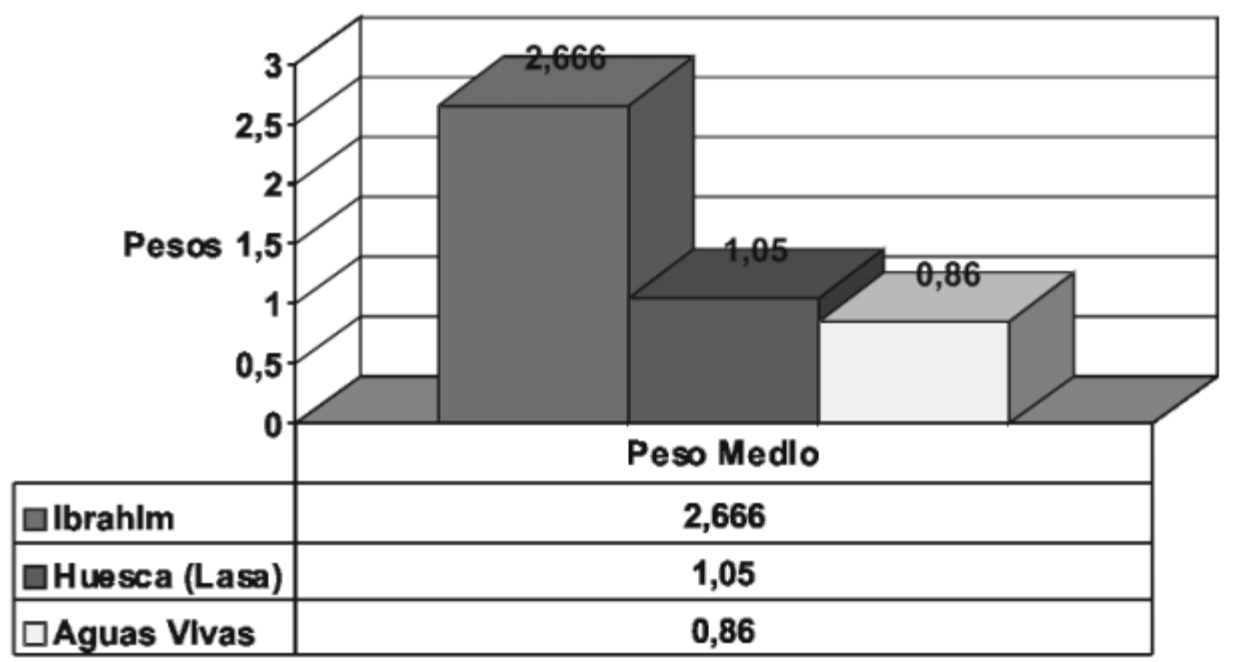

Fig. IOb. Comparación con el peso medio de otros conjuntos. 


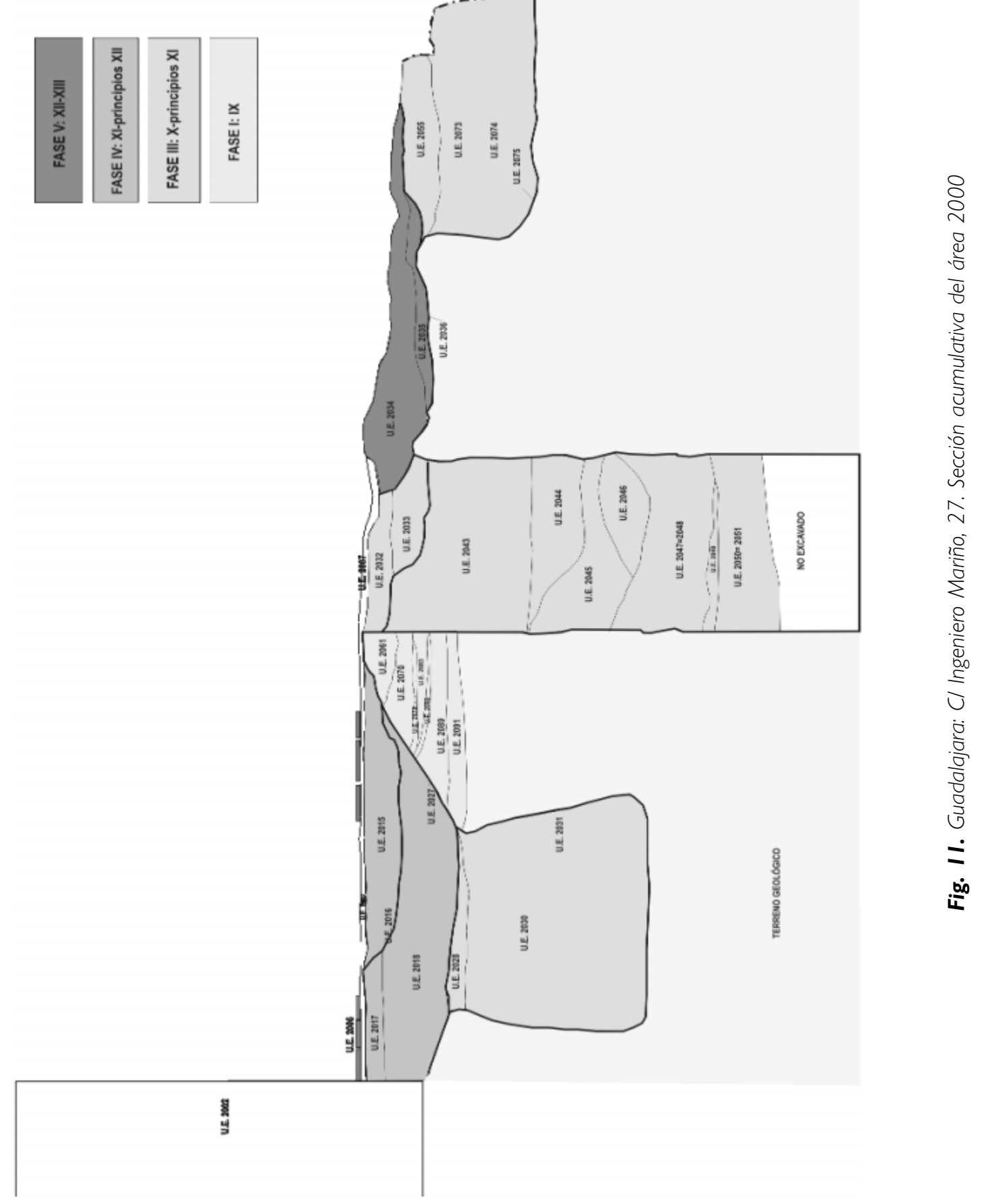




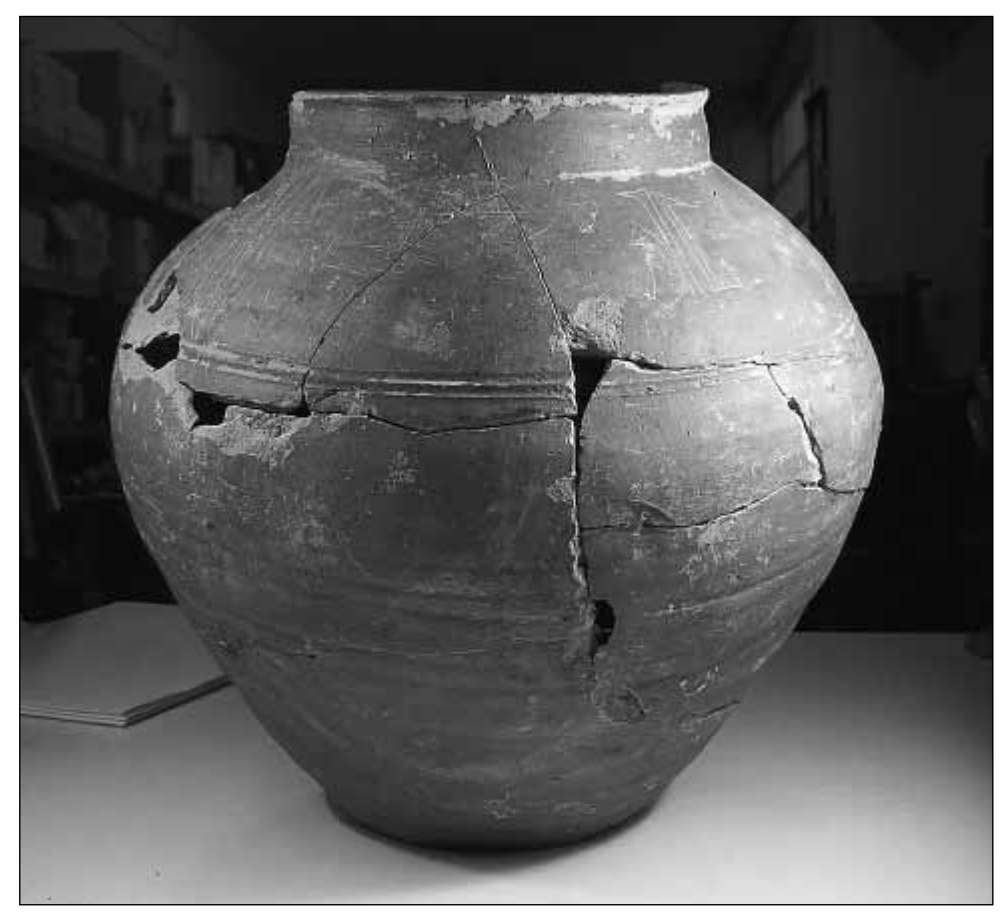

Lám. I. Orza con la inscripción

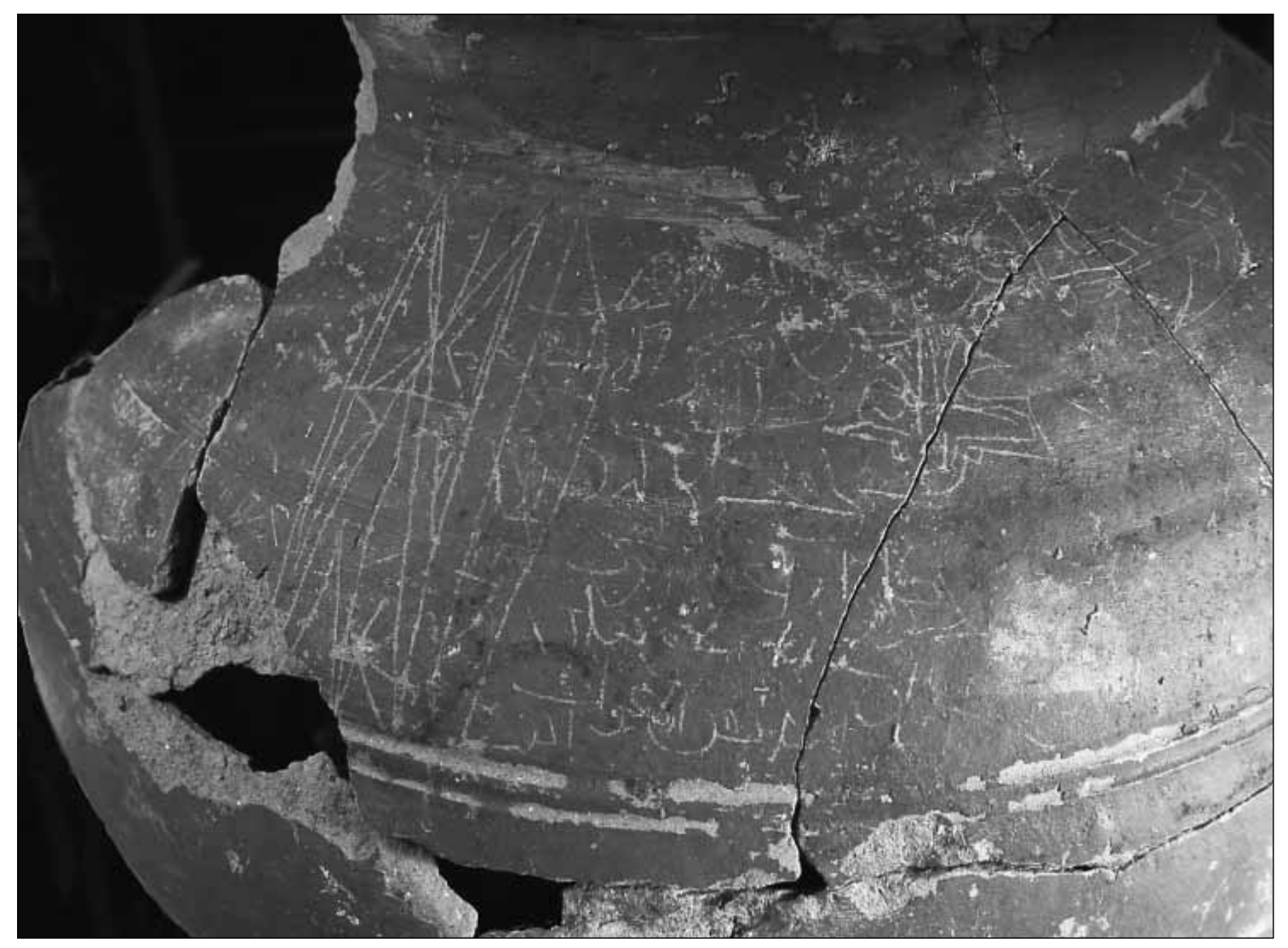

Lám. 2. Detalle de la inscripción 

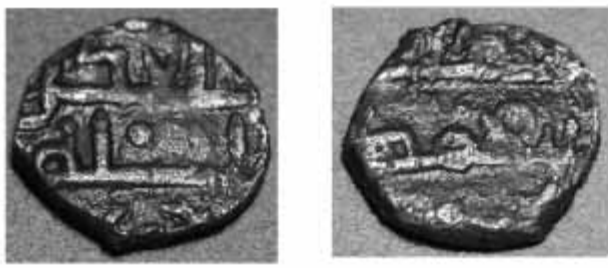

Moneda 1. Anverso y Reverso
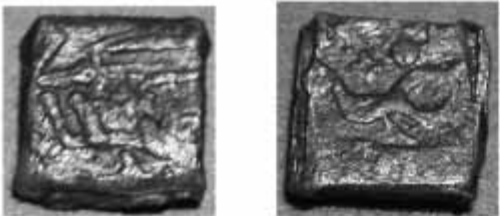

Moneda 4. Anverso y Reverso
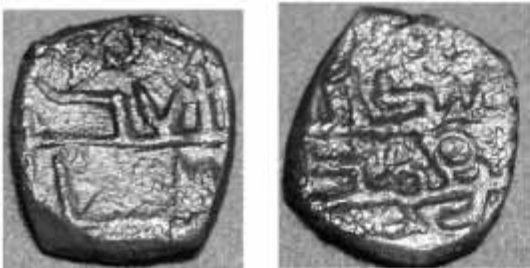

Moneda 8. Anverso y Reverso
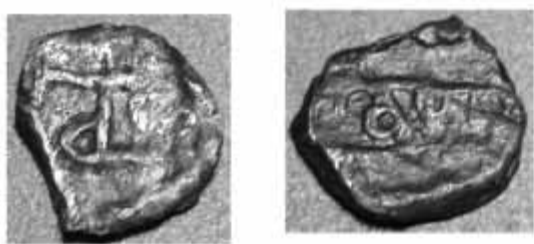

Moneda 14. Anverso y Reverso
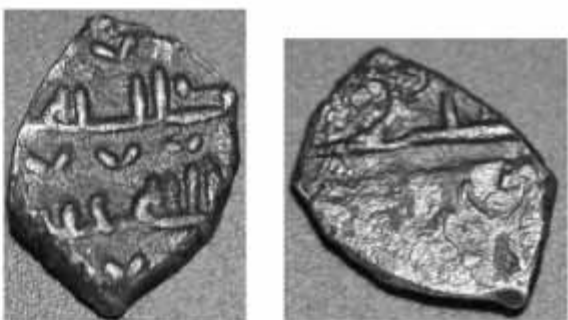

Moneda 3. Anverso y Reverso
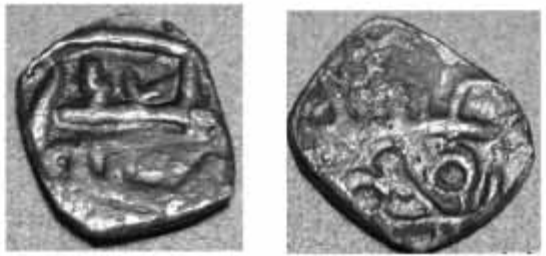

Moneda 6. Anverso y Reverso
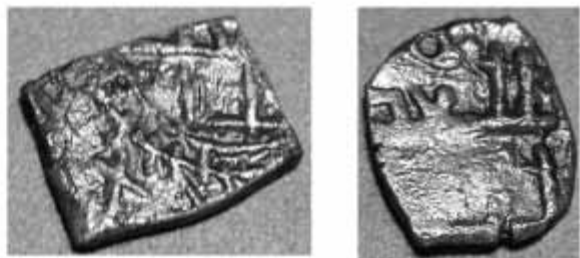

Monedas 9 y 10.
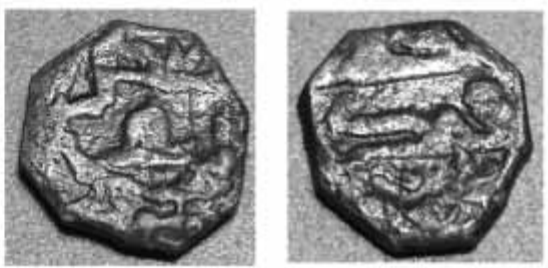

Moneda 21. Anverso y Reverso

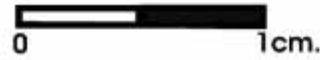

Lám. 3. Tipos principales 